\title{
The white matter tracts of the cerebrum in ventricular surgery and hydrocephalus
}

\author{
Abuzer Güngör, MD, ${ }^{1}$ Serhat Baydin, MD, ${ }^{1}$ Erik H. Middlebrooks, MD,, ${ }^{2,3}$ Necmettin Tanriover, MD, ${ }^{4}$ \\ Cihan Isler, MD, ${ }^{4}$ and Albert L. Rhoton Jr., MD ${ }^{1}$
}

Departments of ${ }^{1}$ Neurosurgery and ${ }^{2}$ Radiology, and the ${ }^{3} \mathrm{~K}$. Scott and E. R. Andrew Advanced Neuroimaging Lab, College of Medicine, University of Florida, Gainesville, Florida; and ${ }^{4}$ Department of Neurosurgery, Cerrahpasa Medical Faculty, Istanbul University, Istanbul, Turkey

OBJECTIVE The relationship of the white matter tracts to the lateral ventricles is important when planning surgical approaches to the ventricles and in understanding the symptoms of hydrocephalus. The authors' aim was to explore the relationship of the white matter tracts of the cerebrum to the lateral ventricles using fiber dissection technique and MR tractography and to discuss these findings in relation to approaches to ventricular lesions.

METHODS Forty adult human formalin-fixed cadaveric hemispheres (20 brains) and 3 whole heads were examined using fiber dissection technique. The dissections were performed from lateral to medial, medial to lateral, superior to inferior, and inferior to superior. MR tractography showing the lateral ventricles aided in the understanding of the 3D relationships of the white matter tracts with the lateral ventricles.

RESULTS The relationship between the lateral ventricles and the superior longitudinal I, II, and III, arcuate, vertical occipital, middle longitudinal, inferior longitudinal, inferior frontooccipital, uncinate, sledge runner, and lingular amygdaloidal fasciculi; and the anterior commissure fibers, optic radiations, internal capsule, corona radiata, thalamic radiations, cingulum, corpus callosum, fornix, caudate nucleus, thalamus, stria terminalis, and stria medullaris thalami were defined anatomically and radiologically. These fibers and structures have a consistent relationship to the lateral ventricles.

CONCLUSIONS Knowledge of the relationship of the white matter tracts of the cerebrum to the lateral ventricles should aid in planning more accurate surgery for lesions within the lateral ventricles.

https://thejns.org/doi/abs/10.3171/2016.1.JNS152082

KEY WORDS fiber dissection; fiber tracts; hydrocephalus; microsurgical anatomy; tractography; ventricular surgery

$\mathrm{S}$ URGICAL approaches to the lateral ventricle always require passage through one and often multiple fiber tracts to reach their target. These approaches remain a challenge because of the deep location and variable shape and size of the ventricles, their covering mantle of tracts, and relationships to important neural structures such as the thalamus and internal capsule..$^{55,75,84}$ In addition, a number of tracts course in the walls of the ventricle where they are separated from the cerebrospinal fluid by only a thin layer of ependyma and would likely be exposed to the greatest possibility of damage by hydrocephalus ${ }^{84,124}$ Recent studies have focused on the relationships of the fiber tracts to eloquent cortical areas and avoiding the optic radiations in approaches to the lateral ventricle. . $6,41,48,59,63,75,89,92,94,125$ The aim of the present study was to explore the relationships of the tracts to the lateral ventricles and the various surgical approaches to the ventricles and to examine the anatomy and syndromes related to ventricular enlargement.

\section{Methods}

Forty adult human formalin-fixed cadaveric hemispheres (20 brains) were examined under magnification that ranged from $\times 6$ to $\times 40$. The dura, pia, arachnoid, and surface vessels were gently removed. All specimens were frozen in water for at least 2 weeks at $-16^{\circ} \mathrm{C}$, as described by Klingler, to separate the tracts and facilitate dissection..$^{51}$ After freezing, the specimens were thawed and rinsed of formalin under tap water for at least 1 hour. Prior

ABBREVIATIONS AD = Alzheimer's disease; $A F=$ arcuate fasciculus; FA = fractional anisotropy; IFOF = inferior frontooccipital fasciculus; ILF = inferior longitudinal fasciculus; $L G B=$ lateral geniculate body; Li-Am = lingular amygdaloidal; MdLF = middle longitudinal fasciculus; $N P H=$ normal pressure hydrocephalus; PD = Parkinson's disease; SLF = superior longitudinal fasciculus; UF = uncinate fasciculus; VOF = vertical occipital fasciculus.

SUBMITTED September 3, 2015. ACCEPTED January 14, 2016.

INCLUDE WHEN CITING Published online June 3, 2016; DOI: 10.3171/2016.1.JNS152082. 
to dissection, the sulci and gyri were studied and photographed in detail. Dissections were performed with microdissectors under the surgical microscope, and between dissections the specimens were stored in a $70 \%$ alcohol solution. The dissections were performed from lateral to medial, medial to lateral, superior to inferior, and inferior to superior.

The relationships between white matter tracts and the ventricles were shown using a technique called transillumination, by introducing a $0^{\circ} 4$-mm-diameter endoscope light source into the ventricle via the posterior transcallosal approach. ${ }^{87}$ Transillumination provides information about the relationships of the tracts to the ventricle and their direction of passage. Some illustrations of the tracts were lightly colored to increase their definition in photographs.

Diffusion MRI was performed using a modified 3-T Siemens Skyra imager (Siemens AG). The acquisition sequence is a spin-echo echo planar imaging sequence, which utilizes multiband image acceleration. ${ }^{23,31,71,91,115}$ The specific sequence parameters are as follows: TR 5520 msec; TE 89.5 msec; FOV $210 \times 180$; matrix $168 \times 144$; slice thickness $1.25 \mathrm{~mm}$ (voxel size $1.25 \times 1.25 \times 1.25 \mathrm{~mm}$ ); multiband factor 3; and b-values 1000 (95 directions), 2000 (96 directions), and $3000 \mathrm{sec} / \mathrm{mm}^{2}$ (97 directions). The raw diffusion data were preprocessed with eddy current and motion correction, b0 intensity normalization, susceptibility distortion correction, and gradient-nonlinearity corrections. ${ }^{2,3,31,43}$ A T1-weighted 3D MPRAGE (magnetization-prepared rapid acquisition gradient echo) scan was registered to the diffusion data for anatomical detail. All preprocessing steps were performed with FreeSurfer (http://surfer.nmr.mgh.harvard.edu) and FSL (http://fsl.fmrib.ox.ac.uk). ${ }^{27,44}$ The preprocessed diffusion data were analyzed with DSI Studio (http://dsi-studio.labsolver.org). The diffusion orientation distribution function was estimated using a generalized q-sampling imaging algorithm. ${ }^{123}$ Streamline fiber tracking was performed by seeding regions of interest based on findings from dissection data in this study.

\section{Results}

The lateral ventricles are C-shaped cavities situated deep within the cerebrum that wrap around the thalamus. The lateral ventricles have 5 parts-the frontal horn, body, atrium, and occipital and temporal horns-and are connected to the third ventricle by the foramen of Monro. The frontal horn is positioned deep to the pars triangularis and pars opercularis on the cortical surface and to the middle and posterior short gyri on the insular surface ${ }^{84,98}$ The body lies deep to the inferior part of the precentral and postcentral gyri on the cortical surface and the superior part of the posterior short gyrus, and to the anterior and posterior long gyri on the insular surface (Figs. 1A, 1B, and 6A) ${ }^{84,98}$ The atrium and occipital horn, located posterior to the junction of the corpus callosum and fornix, are positioned deep to the supramarginal, angular, posterior part of the superior and middle temporal, and to the anterior part of the middle occipital gyrus. The temporal horn is positioned deep to the anterior and mid part of the middle temporal gyrus (Fig. 1A and 1B). ${ }^{84}$

\section{Fiber Tracts of the Cerebrum}

Removing the cortex from the lateral surface of the hemisphere exposes the superior longitudinal fasciculus (SLF) II and III. The SLF II is located superolateral to the frontal horn, body, and atrium (Table 1). It appears as a wavy long association fiber tract connecting the angular gyrus and the mid and anterior part of the middle frontal gyrus and pars opercularis and pars triangularis. It passes deep to the inferior parietal lobule, middle part of the preand postcentral gyri, and middle frontal gyrus (Figs. 1C, $1 \mathrm{D}$, and $6 \mathrm{~A}-\mathrm{C}$ ).

The SLF III is located lateral to the superior two-thirds of the frontal horn and body of the lateral ventricle and to the anterosuperior edge of the atrium, and it courses just inferior and lateral to the SLF II, connecting the supramarginal gyrus to the mid and anterior part of the inferior frontal gyrus. It passes deep to the inferior part of the preand postcentral gyri and part of the supramarginal and inferior frontal gyri. There is no clear demarcation between the SLF II and SLF III (Figs. 1C, 1D, and 6A-C).

Removing the SLF II and III and the U-fibers of the temporal and occipital lobes exposes the arcuate (AF) and vertical occipital (VOF) fasciculi. This study separated the AF into 3 parts - superior, central, and inferior-to clarify its relationship with the lateral ventricle. The superior part of the AF extends from the inferior and middle frontal gyri to the posterior insular point (junction of the inferior and superior limiting insular sulci) and runs lateral to the superior two-thirds of the frontal horn and body of the lateral ventricle (Figs. 2A-C and 7D-F). The central part of the AF runs from the posterior insular point to the angular gyrus and lateral to the anterior two-thirds of the atrium. The inferior part of the AF runs from the level of the posterior insular point to the anterior tip of the temporal horn (Table 1). The AF wraps around the posterior edge of the insula in a horseshoe-like configuration; connects the mid, posterior, and anterior parts of the middle and superior temporal gyri to the mid parts of the inferior and middle frontal gyri; and passes deep to the middle and superior part of the lateral surface of the temporal lobe, anterior part of the occipital lobe, angular and supramarginal gyri, middle and inferior parts of the pre- and postcentral gyri, and anterior and middle parts of the middle and inferior frontal gyri (Table 2). It is difficult to separate the anterior part of the AF from the SLF II and III because they course in the same direction adjacent to each other.

The VOF runs lateral to the posterior one-third of the atrium. It is located just posterior to the AF (Table 1). It ascends obliquely and connects the inferior occipital lobe to the lateral superior occipital lobe and angular gyrus (Fig. 2A-C). This connection suggests that the VOF has an important role in reading and facial recognition (Table 2). ${ }^{49,96,121}$ The VOF has a close relationship with the posterior part of the $\mathrm{AF}$.

Removing the posterior part of the AF and VOF exposes the middle and inferior longitudinal fasciculi (MdLF and ILF). The MdLF can be separated into 2 parts - anterior and posterior-based on its relationship with the lateral ventricle. The anterior part, from the temporal pole to the posterior insular point, runs superior to the temporal 

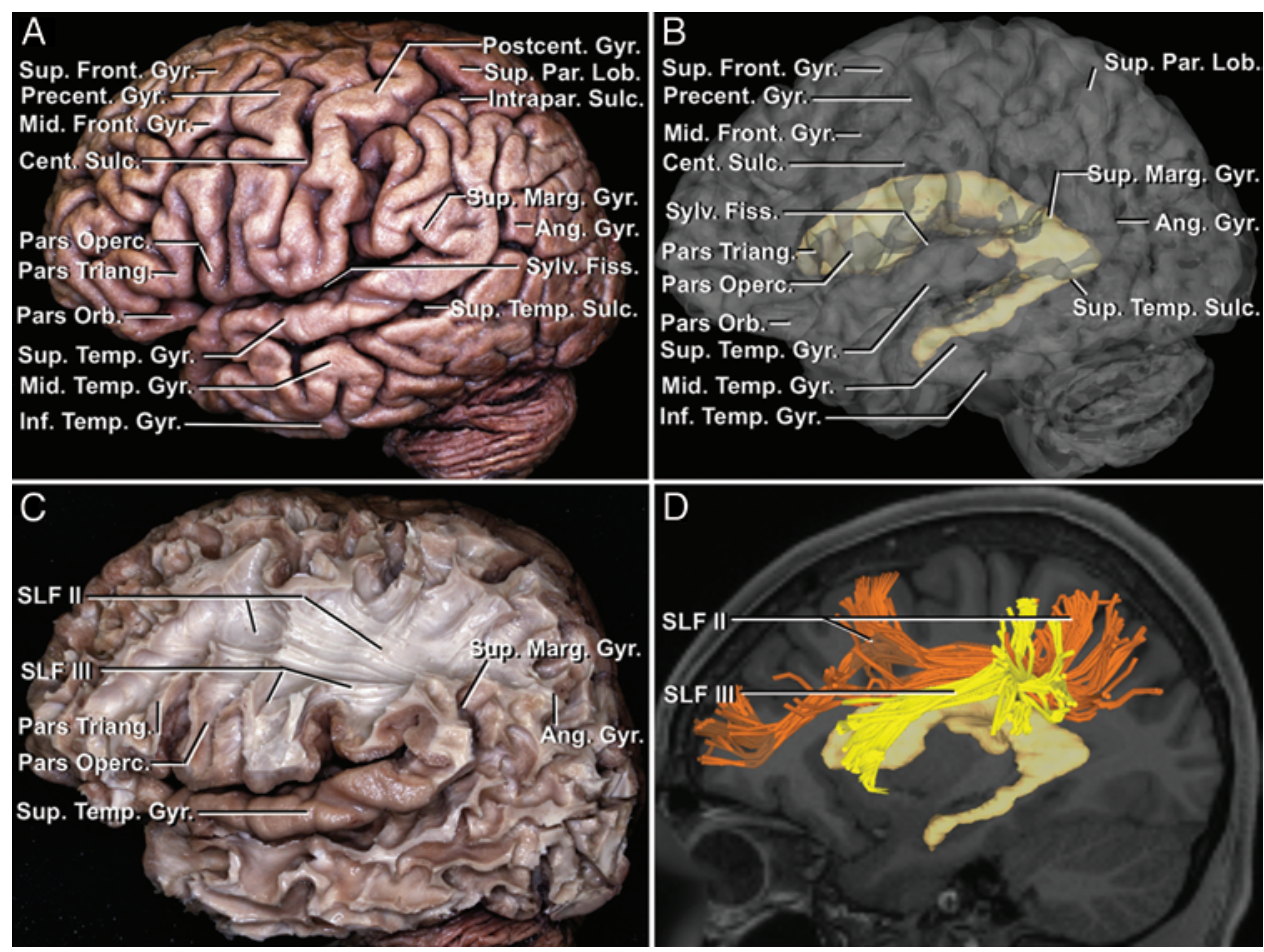

FIG. 1. Fiber dissection from lateral to medial, MR tractography from lateral (Figs. 1-5). A: Sulci and gyri on the lateral surface. Left hemisphere. B: 3D reconstruction of MR images to show cortical relationships of the lateral ventricle. C: Removing the lateral cortical surface and the short association fibers exposes the superior longitudinal fasciculus (SLF) II and the SLF III. D: SLF II (orange) and SLF III (yellow) fibers on MR tractography. The SLF II is positioned superolateral to the frontal horn, body, and atrium of the lateral ventricle. The SLF III is positioned lateral to the superior two-thirds of the frontal horn and body of the lateral ventricle and superior edge of the atrium. Ang. = angular; Cent. = central; Fiss. = fissure; Front. = frontal; Gyr. = gyrus; Inf. = inferior; Intrapar. $=$ intraparietal; Lob. = lobule; Marg. = marginal; Mid. = middle; Operc. = opercularis; Orb. = orbitalis; Par. = parietal; Postcent. $=$ postcentral; Precent. = precentral; SLF = superior longitudinal fasciculus; Sulc. = sulcus; Sup. = superior; Sylv. = sylvian; Temp. $=$ temporal; Triang. $=$ triangularis.

horn. The part posterior to the level of the posterior insular point runs lateral to the middle one-third of the atrium (Table 1). The MdLF connects the temporal pole and the superior temporal gyrus to the angular gyrus and superior occipital lobe and merges with the sagittal stratum after exiting the superior temporal gyrus (Figs. 2D-F and $8 \mathrm{~A}-\mathrm{C}$ ). The MdLF may have a role in the dorsal pathway of the auditory system (Table 2). ${ }^{61,67,110}$

The ILF runs inferolateral to the temporal horn and atrium (Table 1). It connects the temporal pole with the dorsolateral occipital cortex and passes deep to the inferior temporal and inferior occipital gyri at the inferolateral edge of the temporal lobe (Figs. 2D-F, 3A-C, and 11A-D) (Table 2). The ILF forms a ventral occipitotemporal processing pathway with the inferior frontooccipital fasciculus (IFOF), which is considered to be involved in visual identification and pattern discrimination, connecting regions of the core system of facial recognition (Table 3). $., 35,72$

Removing the insular cortex and extreme capsule, the anterior part of the AF, and the MdLF exposes the external capsule and corona radiata. The external capsule with its fanlike shape divides into 2 parts: a dorsal part, formed by the claustrocortical fibers, and a ventral part, formed by the IFOF and uncinate fasciculus (UF). In this study, the IFOF was divided into anterior and posterior parts based on its relationship to the central insular sulcus. The anterior part of the IFOF runs lateral to the inferior two-thirds of the frontal horn and the posterior part runs lateral to the temporal horn and inferior two-thirds of the atrium to reach the occipital lobe (Table 1). The IFOF connects the anterior and mid parts of the inferior and middle frontal gyri with the temporal and occipital lobes, and it passes deep to the full length of the limen insula, superior and middle temporal gyri, and middle and inferior occipital gyri (Figs. 3A-C and 8D-F; Table 2). The IFOF narrows at the limen insula level into a bowtie shape and has a close relationship with, and runs in the same direction as, the corona radiata anteriorly and sagittal stratum posteriorly after passing deep to the anterior and posterior limiting sulci. The IFOF runs through the temporal and occipital lobes just above the ILF. Our dissections reveal that at the insular level, the IFOF passes deep to the inferior half of the posterior long insular gyrus and inferior third of the anterior long gyrus and the anterior, middle, and posterior short insular gyri.

The UF is divided into anterosuperior and posteroinferior parts at the central insular sulcus to clarify its relationship with the ventricle. The anterosuperior part of the UF runs inferior and inferolateral to the frontal horn, and the posteroinferior part courses anterior to the temporal horn (Table 1). The hooklike UF connects the orbitofrontal and 
TABLE 1. Relationship of the tracts to the lateral ventricle

\begin{tabular}{|c|c|}
\hline Ventricular Wall & Related Tracts \\
\hline \multicolumn{2}{|l|}{ Frontal horn } \\
\hline Lateral & $\begin{array}{l}\text { SLF III, AF, IFOF, claustrocortical, frontopontine, } \\
\text { AFTR, SFTR, VCF, UF }\end{array}$ \\
\hline Medial & Forceps minor, CC, septum pellucidum \\
\hline Inferior & UF, cingulum, rostrum of corpus callosum \\
\hline Superior & SLF I, SLF II, cingulum, CC \\
\hline Anterior & Cingulum, $\mathrm{CC}$ \\
\hline \multicolumn{2}{|l|}{ Body } \\
\hline Lateral & $\begin{array}{l}\text { SLF III, AF, claustrocortical, frontopontine, SFTR, } \\
\text { VCF, caud nucl, CST, PTR }\end{array}$ \\
\hline Medial & Septum pellucidum \\
\hline Inferior & $\begin{array}{l}\text { Body of fornix, anterior commissure, thalamus, } \\
\text { choroid plexus, stria medullaris thalami, stria } \\
\text { terminalis }\end{array}$ \\
\hline Superior & SLF I, SLF II, cingulum, CC \\
\hline \multicolumn{2}{|l|}{ Atrium } \\
\hline Lateral & $\begin{array}{l}\text { AF, claustrocortical, parietopontine, PTR, tapetum, } \\
\text { MdLF, IFOF, occipitopontine, tapetum, VOF, } \\
\text { anterior commissure, optic radiations }\end{array}$ \\
\hline Medial & Cingulum, sledge runner, forceps major \\
\hline Inferior & Li-Am, anterior part of the optic radiations \\
\hline Superior & Tapetum, SLF I, cingulum, tapetum \\
\hline Anterior & Crura of fornix, thalamus, choroid plexus, caud nucl \\
\hline \multicolumn{2}{|l|}{ Temporal horn } \\
\hline Lateral & $\begin{array}{l}\text { AF, IFOF, occipitotemporopontine, anterior commis- } \\
\text { sure, optic radiations, tapetum }\end{array}$ \\
\hline Medial & Thalamus, hippocampus, fimbria of fornix \\
\hline Inferior & Cingulum, Li-Am, anterior part of the optic radiations \\
\hline Superior & MdLF, tail of caud nucl, choroid plexus \\
\hline Anterior & $\begin{array}{l}\text { UF, temporal extension of anterior commissure, } \\
\text { amygdala }\end{array}$ \\
\hline \multicolumn{2}{|l|}{ Occipital horn } \\
\hline Lateral & $\begin{array}{l}\text { VOF, IFOF, occipitopontine, anterior commissure, } \\
\text { central part of the optic radiations, tapetum }\end{array}$ \\
\hline Medial & Forceps major, sledge runner \\
\hline Inferior & Anterior part of the optic radiations \\
\hline Superior & Tapetum \\
\hline
\end{tabular}

$\mathrm{AF}=$ arcuate fasciculus; $\mathrm{AFTR}=$ anterior frontal thalamic radiations; caud nucl = caudate nucleus; $\mathrm{CC}=$ corpus callosum; $\mathrm{CST}=$ corticospinal tract; IFOF = inferior frontooccipital fasciculus; $\mathrm{Li}$-Am = lingular amygdaloidal; MdLF $=$ middle longitudinal fasciculus; $\mathrm{PTR}=$ parietal thalamic radiations; SFTR = superior frontal thalamic radiations; SLF = superior longitudinal fasciculus; UF = uncinate fasciculus; $\mathrm{VCF}=$ ventral callosal fibers; $\mathrm{VOF}=$ vertical occipital fasciculus.

septal areas to the anterior part of the temporal lobe and passes just inferior to the IFOF and deep to the anterior part of the temporal lobe, limen insula, and frontoorbital cortex (Figs. 5A, 5C, 9A, 9D, and 11A-C). Recent studies suggest that the UF plays a role in reward- and punishment-based behavioral decisions as a part of the ventral limbic pathway (Table 3). ${ }^{102,108}$ The dorsal external capsule fibers, formed by claustrocortical fibers, run lateral to the posterior one-third of the frontal horn, body, and anterior one-third of the atrium, and they connect the claustrum to the frontal and parietal lobes (Table 1). The external and internal capsule fibers join at the upper edge of the putamen to form the corona radiata, which courses through the superior part of the frontal and parietal lobes, where they join the callosal fibers to form the centrum semiovale (Fig. $8 \mathrm{~A}-\mathrm{E})$.

Removing the IFOF, dorsal external capsule and putamen, and internal capsule fibers exposes the anterior commissure and globus pallidus. The anterior commissure consists of a body, anterior and posterior crura, and the occipital and temporal extensions of the posterior crus. The body of the anterior commissure crosses the midline in the anterior wall of the third ventricle and bifurcates into anterior and posterior crura. The anterior crus passes forward to the medial orbitofrontal area and the posterior crus runs superolaterally to reach the temporal lobe, where it gives extensions to the temporal pole and occipital lobe. The occipital extension merges into the sagittal stratum after passing deep to the inferior limiting sulcus (Figs. 3D-F, 4A, 4B, 9A-C, 10G, and 12A). The anterior crus passes forward below the frontal horn. The temporal extension passes anterior to the temporal horn and the occipital extension runs lateral to the inferior two-thirds of the atrium (Figs. 3D-F and 9A-C; Table 2).

The internal capsule includes the corticopontine and corticospinal tract fibers and the thalamic radiations. The internal capsule consists of 5 parts: the anterior limb, genu, posterior limb, and the retro- and sublenticular parts. The anterior limb includes the anterior and superior frontal thalamic radiations and frontopontine tract and runs lateral to the frontal horn and anterior one-third of the body of the lateral ventricle. The genu of the internal capsule includes the anterior part of the corticobulbar and corticospinal tracts and the posterior part of the superior frontal thalamic radiations and runs lateral to the mid part of the body of the lateral ventricle. The posterior limb includes the posterior part of the corticospinal tract and the parietal thalamic radiations and parietopontine fibers and runs lateral to the posterior two-thirds of the body of the lateral ventricle and superior one-third of the atrium to form the corona radiata with the external capsule fibers (Table 1). ${ }^{24}$ The corticospinal tract arises at the precentral gyrus and descends lateral to the mid one-third of the body of the lateral ventricle (Figs. 9E, 9F, 9H, 15D, and 15E; Table 1). The retrolenticular part of the internal capsule includes the parietopontine fibers and a small part of the occipital thalamic radiations, and the sublenticular part contains occipitopontine and temporopontine fibers and the anterior component of the occipital thalamic radiations. The retro- and sublenticular parts, which include the optic radiations, run lateral to the temporal horn and inferior twothirds of the atrium to join the sagittal stratum (Figs. 3D, $3 \mathrm{E}, 4 \mathrm{~A}$, and $4 \mathrm{~B}) .^{25,33}$

The thalamic radiations are divided into 5 parts according to their cortical origins: anterior frontal, superior frontal, parietal, occipital, and temporal. ${ }^{117}$ In our dissections, different parts of the thalamic radiations passed lateral to distinct parts of the lateral ventricle. The anterior frontal thalamic radiations run lateral to the inferior two-thirds of the frontal horn. The superior frontal thalamic radiations 

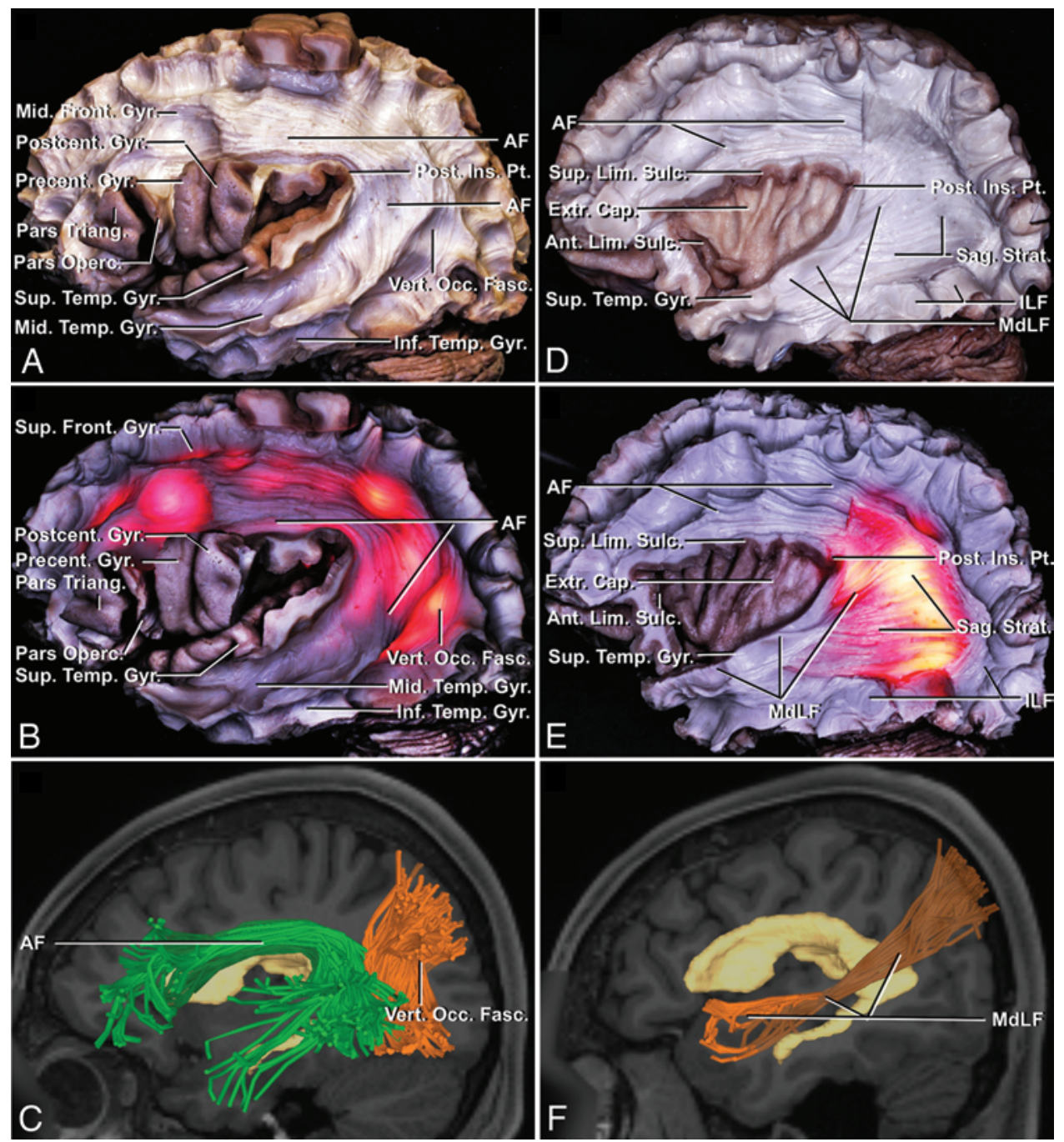

FIG. 2. A: The superior temporal gyrus has been preserved. Removing the superior longitudinal fasciculus II and III and the $\mathrm{U}$-fibers of the temporal and occipital lobes exposes the arcuate fasciculus (AF) and vertical occipital fasciculus (VOF). The VOF runs in an oblique direction from the superior occipital gyrus to the fusiform gyrus just posterior the AF. B: An endoscopic light source placed in the ventricle through the transcallosal approach transilluminates and shows the relationship between white matter tracts and ventricles. ${ }^{87}$ The AF lies lateral to the superior two-thirds of the frontal horn and body, the anterior two-thirds of the atrium, and the temporal horn. The VOF is lateral to the posterior one-third of the atrium. C: AF (green) and VOF (orange) relationships with the ventricle, shown with MR tractography. D: The anterior, posterior, and inferior insular sulci and inferior part of the limen insula have been preserved to show the edges of the insula. Removing the posterior part of the AF exposes the middle (MdLF) and inferior (ILF) longitudinal fasciculi. Removing the cortex of the insula exposes the extreme capsule. E: Transillumination shows the relationships of the MdLF and ILF with the ventricle. The MdLF courses superior to the temporal horn and lateral to the middle one-third of the atrium. The ILF courses inferolateral to the temporal horn, atrium, and occipital horn. F: MdLF (orange) relationship with the ventricle, shown with MR tractography. AF = arcuate fasciculus; Ant. = anterior; Cap. = capsule; Extr. $=$ extreme; Fasc. $=$ fasciculus; Front. = frontal; Gyr. = gyrus; ILF = inferior longitudinal fasciculus; Inf. = inferior; Ins. = insular; Lim. = limiting; MdLF = middle longitudinal fasciculus; Mid. = middle; Occ. = occipital; Operc. = opercularis; Post. = posterior; Postcent. $=$ postcentral; Precent. = precentral; Pt. = point; Sag. Strat. = sagittal stratum; Sulc. = sulcus; Sup. = superior; Temp. = temporal; Triang. $=$ triangularis; Vert. $=$ vertical .

run lateral to the superior one-third of the frontal horn and the anterior two-thirds of the body of the lateral ventricle. The parietal thalamic radiations run lateral to the posterior one-third of the body and superior one-third of the atrium (Figs. 4D, 4E, and 15A-C; Table 1).

Removing the posterior part of the posterior crus of the anterior commissure exposes the occipital and temporal thalamic radiations (optic radiations) running lateral to the temporal horn and inferior two-thirds of the atrium (Table 1) ${ }^{87}$ Our dissections revealed 3 distinct subcomponents of optic radiations-anterior, central, and posterior-based on their course and termination in relation to the lateral ventricle. The anterior part of the optic radiations crosses the roof and lateral wall of the anterior one-third of the temporal horn, inferolateral edge of the temporal horn, and the lateral part of the floor of the atrium. The central 


\section{A. Güngör et al.}

TABLE 2. Fiber tracts: connections, functional role, and disconnection syndromes

\begin{tabular}{|c|c|c|c|c|}
\hline \multirow[b]{2}{*}{ Fiber Tract } & \multirow[b]{2}{*}{ Connection } & \multicolumn{2}{|c|}{ Functional Role } & \multirow[b]{2}{*}{ Disconnection Syndrome } \\
\hline & & Dominant Hemisphere & Nondominant Hemisphere & \\
\hline $\begin{array}{l}\text { SLF }\left.\right|^{46,100}, \\
\quad 109,111,116,117\end{array}$ & Precuneus-superior frontal gyrus & \multicolumn{2}{|c|}{$\begin{array}{l}\text { Higher-order control of body-centered action, initia- } \\
\text { tion of motor activity }\end{array}$} & Unknown \\
\hline $\begin{array}{c}\text { SLF } \|^{6,14,68,88,} \\
99,100,116,117\end{array}$ & $\begin{array}{l}\text { Angular gyrus-pars triangularis, } \\
\text { midpart of the middle \& inferior } \\
\text { frontal gyri }\end{array}$ & \multicolumn{2}{|c|}{ Visual \& oculomotor aspects of spatial function } & Spatial hemineglect, Gerstmann syndrome \\
\hline $\begin{array}{l}\text { SLF III19,62, } \\
\quad 99,116,117\end{array}$ & $\begin{array}{l}\text { Supramarginal gyrus-anterior } \\
\text { part of the inferior frontal gyrus }\end{array}$ & $\begin{array}{l}\text { Articulation, working } \\
\text { memory }\end{array}$ & Visuospatial attention & Spatial hemineglect, dysarthria, anarthria \\
\hline $\begin{array}{l}\mathrm{AF}^{6,13,17,19,25} \\
64,78,103,105 \\
116,117\end{array}$ & $\begin{array}{l}\text { Anterior, mid, \& posterior parts of } \\
\text { the temporal gyrus-midpart of } \\
\text { the inferior \& middle frontal gyri }\end{array}$ & $\begin{array}{l}\text { Lexical, semantic, \& } \\
\text { phonological lan- } \\
\text { guage processing }\end{array}$ & $\begin{array}{l}\text { Perception \& production of } \\
\text { nonlinguistic communi- } \\
\text { cation }\end{array}$ & $\begin{array}{l}\text { Transcortical motor aphasia, phono- } \\
\text { logical paraphasia, \& repetition disorder } \\
\text { aphasia }\end{array}$ \\
\hline VOF $^{49,96,121,122}$ & $\begin{array}{l}\text { Inferior occipital gyrus-lateral oc- } \\
\text { cipital lobe, angular gyrus }\end{array}$ & \multicolumn{2}{|c|}{ Object recognition, reading } & Pure alexia \\
\hline MdLF88,61,67,110 & $\begin{array}{l}\text { Temporal pole-angular gyrus, } \\
\text { superior occipital lobe }\end{array}$ & \multicolumn{2}{|c|}{ Processing the spatial features of sounds } & Unknown \\
\hline $\operatorname{ILF}^{13,25,35,88}$ & $\begin{array}{l}\text { Temporal pole-dorsolateral oc- } \\
\text { cipital cortex }\end{array}$ & \multicolumn{2}{|c|}{$\begin{array}{l}\text { Recognition \& identification of visually perceived } \\
\text { objects }\end{array}$} & $\begin{array}{l}\text { Progressive prosopagnosia, visual agnosia, } \\
\text { alexia }\end{array}$ \\
\hline $\begin{array}{l}\text { IFOF }^{6,13,25} \\
88,105,117\end{array}$ & $\begin{array}{l}\text { Anterior \& midparts of the frontal } \\
\text { gyrus-occipital lobe }\end{array}$ & $\begin{array}{l}\text { Lexical-semantic } \\
\text { processing, visual } \\
\text { spatial processing }\end{array}$ & $\begin{array}{l}\text { Lexical-semantic process- } \\
\text { ing }\end{array}$ & Semantic paraphasia \\
\hline$A C^{6,25,88,117}$ & $\begin{array}{l}\text { Both the caudate \& lentiform } \\
\text { nuclei, nucleus accumbens, } \\
\text { temporal \& occipital lobes }\end{array}$ & \multicolumn{2}{|c|}{ Olfactory, auditory, \& visual communication } & Verbal anosmia \\
\hline $\begin{array}{l}U^{U} F^{6,25,88} \\
\quad 102,108,117\end{array}$ & $\begin{array}{l}\text { Anterior part of the temporal } \\
\text { lobe-orbitofrontal \& septal } \\
\text { areas }\end{array}$ & \multicolumn{2}{|c|}{$\begin{array}{l}\text { Ventral limbic pathway, reward \& punishment-based } \\
\text { behavioral decisions, mediating the rapid learning } \\
\text { of conditional visual associations }\end{array}$} & $\begin{array}{l}\text { Semantic retrieval, deficit in naming famous } \\
\text { individual, social/emotional problems, } \\
\text { difficulties in learning from punishment }\end{array}$ \\
\hline$\underset{88,117}{\text { Cingulum }}$ & $\begin{array}{l}\text { Subcallosal cortex-anterior part } \\
\text { of the parahippocampal gyrus }\end{array}$ & \multicolumn{2}{|c|}{$\begin{array}{l}\text { Dorsal limbic pathway, regulation of emotional } \\
\text { processing, emotional content of pain perception, } \\
\text { bladder control }\end{array}$} & $\begin{array}{l}\text { Autonomic phenomena, urinary inconti- } \\
\text { nence, behavioral changes including } \\
\text { fear, anxiety, \& pleasure }\end{array}$ \\
\hline $\begin{array}{l}\text { Sledge run- } \\
\text { ner }^{106,113}\end{array}$ & $\begin{array}{l}\text { Posterior part of the precuneus- } \\
\text { lingula }\end{array}$ & \multicolumn{2}{|l|}{ Recognition of places } & Unknown \\
\hline Li-Am F53,54 & Amygdala-lingula & \multicolumn{2}{|c|}{$\begin{array}{l}\text { Developmental \& individual differences in social } \\
\text { cognition }\end{array}$} & Unknown \\
\hline $\begin{array}{l}\text { CC, dorsal } \\
\text { part } 6,7,25,29, \\
117,118\end{array}$ & $\begin{array}{l}\text { Both dorsal parts of the frontal, } \\
\text { parietal, \& occipital lobes }\end{array}$ & \multicolumn{2}{|c|}{ Depends on function of connecting areas } & $\begin{array}{l}\text { Long-term visual \& verbal memory deficits, } \\
\text { dysexecutive cognitive \& behavioral syn- } \\
\text { drome, disturbances in interhemispheric } \\
\text { transfer of motor learning, unilateral } \\
\text { tactile anomia, It hemialexia, unilateral } \\
\text { apraxia, transitory mutism }\end{array}$ \\
\hline $\begin{array}{l}\text { CC, ventral } \\
\text { part } 6,15,25,69 \\
81,85,90,113,117\end{array}$ & $\begin{array}{l}\text { Both caudate nuclei, ventral parts } \\
\text { of frontal parietal \& occipital } \\
\text { lobes, \& entire temporal lobes }\end{array}$ & \multicolumn{2}{|c|}{$\begin{array}{l}\text { Depends on function of connecting areas; executive } \\
\quad \& \text { goal-directed actions }\end{array}$} & Auditory or visual disconnection syndromes \\
\hline Fornix 6,25 & $\begin{array}{l}\text { Intralimbic gyrus-mammillary } \\
\text { body \& septal area }\end{array}$ & \multicolumn{2}{|l|}{ Memory processing } & Amnesia \\
\hline
\end{tabular}

$\mathrm{AC}=$ anterior commissure; $\mathrm{AF}=$ arcuate fasciculus; $\mathrm{CC}=$ corpus callosum; IFOF = inferior frontooccipital fasciculus; ILF = inferior longitudinal fasciculus; $\mathrm{Li}-\mathrm{Am} \mathrm{F}=$ lingular amygdaloid fasciculus; $\mathrm{MdLF}=$ middle longitudinal fasciculus; $\mathrm{SLF}=$ superior longitudinal fasciculus; $U F=$ uncinate fasciculus; VOF = vertical occipital fasciculus.

part of the optic radiations covers the roof and middle onethird of the lateral wall of the temporal horn and the inferior one-third of the floor of the atrium and occipital horn. The posterior part of the optic radiations covers the posterior one-third of the lateral wall of the temporal horn and middle one-third of the lateral wall of the atrium (Table 1). The optic radiations emerge from the lateral geniculate body (LGB) of the thalamus along the lower surface of the thalamus, the termination site of the optic tract. The anterior part of the optic radiations has an anterolateral initial course after it arises from the LGB, then curves backward to form Meyer's loop to reach to the inferior lip of the calcarine sulcus. The central part of the optic radiations runs laterally after exiting from the LGB, then turns posteriorly 

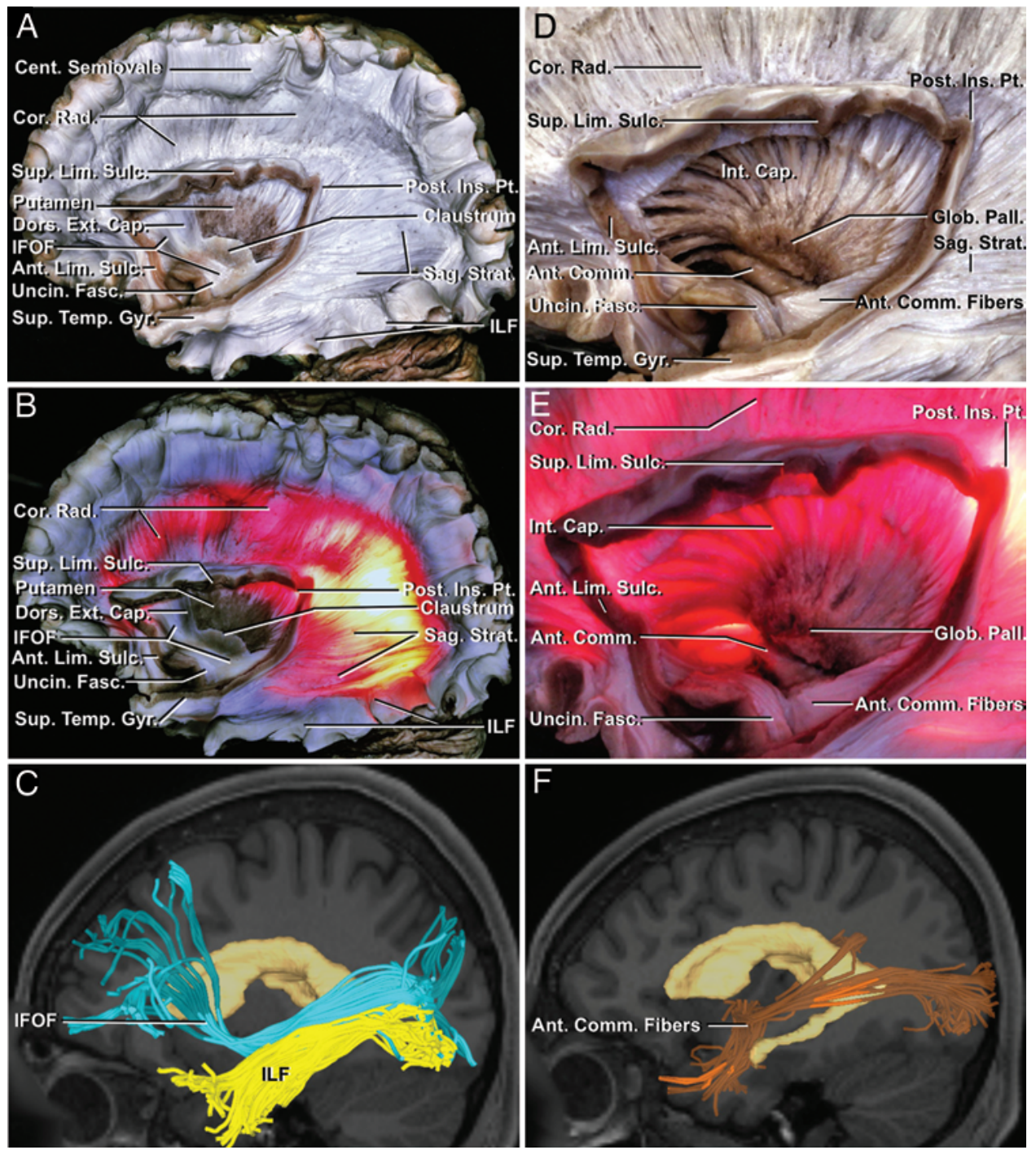

FIG. 3. A: Removing the insular cortex and extreme capsule, anterior part of the arcuate fasciculus, and the middle longitudinal fasciculus exposes the external capsule, inferior frontooccipital (IFOF) and uncinate (UF) fasciculi, and corona radiata. The external and internal capsule fibers join at the edge of the putamen level to form the corona radiata, which runs to the superior part of the frontal and parietal lobes where it joins with the callosal fibers to form the centrum semiovale. B: Transillumination shows the relationships of the corona radiata and IFOF with the ventricle. The posterior part of the IFOF runs lateral to the temporal horn and the inferior two-thirds of the atrium to reach the occipital lobe. The anterior part of the IFOF courses lateral and superior to cover the anterior two-thirds of the frontal horn. The dorsal external capsule fibers (claustrocortical fibers) run lateral and superior to the posterior one-third of the frontal horn and body of the lateral ventricle and superior one-third of the atrium to form part of the corona radiata. The anterior part of the UF covers the inferior surface of the frontal horn and the posterior part of the UF is located anterior to the temporal horn. C: IFOF (blue) and inferior longitudinal fasciculus (yellow) relationships with the ventricle, shown with MR tractography. D: Removing the IFOF and putamen exposes the anterior commissure, internal capsule, and globus pallidus. The internal capsule involves varied fibers connecting the supratentorium structures to the brainstem and joins the external capsule fibers ascending above the level of the upper edge of the putamen to form the corona radiata. E: Transillumination shows the relationship of the anterior commissure and the internal capsule fibers to the ventricle. The anterior limb of the internal capsule runs lateral to the frontal horn and anterior one-third of the body of the lateral ventricle, the genu runs lateral to the mid part of the body of the lateral ventricle, and the posterior limb runs lateral to the posterior two-thirds of the body of the lateral ventricle and superior one-third of the atrium and joins with the external capsule fibers to form the corona radiata. The retro- and sublenticular parts run lateral to the temporal horn and inferior two-thirds of the atrium to join the sagittal stratum. The occipital and temporal extensions of the anterior commissure run lateral to the temporal horn and inferior two-thirds of the atrium. F: Anterior commissure (orange) relationships with the ventricle, shown with MR tractography. Ant. = anterior; $\mathrm{Cap} .=$ capsule; Cent. $=$ centrum; Comm. = commissure; Cor. = corona; Dors. = dorsal; Ext. = external; Fasc. = fasciculus; Glob. = globus; Gyr. = gyrus; IFOF = inferior frontooccipital fasciculus; ILF = inferior longitudinal fasciculus; Ins. = insular; Int. = internal; Lim. = limiting; Pall. = pallidus; Post. = posterior; Pt. = point; Rad. = radiata; Sag. Strat. = sagittal stratum; Sulc. = sulcus; Sup. $=$ superior; Temp. = temporal; Uncin. = uncinate. 
TABLE 3. Operative approaches to the lateral ventricle: lesion location, related tracts, and deficits

\begin{tabular}{|c|c|c|c|}
\hline Approach & Lesion Location & Related Tracts & Related Deficits \\
\hline $\begin{array}{l}\text { Anterior interhemispheric trans- } \\
\text { callosal }\left.\right|^{6,34,48,84,85,90}\end{array}$ & $\begin{array}{l}\text { Frontal horn \& body \& 3rd } \\
\quad \text { ventricle }\end{array}$ & Genu \& body of corpus callosum & $\begin{array}{l}\text { Frontal disconnection syndrome (deficits } \\
\text { of visual \& verbal memory, dysexecu- } \\
\text { tive cognitive \& behavioral syndrome, } \\
\text { \& disturbances in interhemispheric } \\
\text { transfer of motor learning) }\end{array}$ \\
\hline $\begin{array}{l}\text { Anterior frontal transcortical } \\
22,48,68,70,77,82,84,86,95,99,105\end{array}$ & $\begin{array}{l}\text { Frontal horn, anterior part of the } \\
\text { body, \& anterior or superior } \\
\text { part of the 3rd ventricle }\end{array}$ & $\begin{array}{l}\text { Anterior part of the SLF II, AF, \& } \\
\text { IFOF, corona radiata fibers \& } \\
\text { ventral callosal fibers (if the } \\
\text { route goes medially, also SLF I \& } \\
\text { cingulum) }\end{array}$ & $\begin{array}{l}\text { Language disorders, limbic system } \\
\text { dysfunction, dysfunction of spatial } \\
\text { awareness }\end{array}$ \\
\hline
\end{tabular}

\begin{tabular}{|c|c|c|c|}
\hline $\begin{array}{l}\text { Anterior frontal interhemispheric } \\
\text { transrostral } 34,81,84,85,50\end{array}$ & $\begin{array}{l}\text { Floor \& lower part of anterior wall } \\
\text { of frontal horn or lesions that } \\
\text { extend from the rostrum of } \\
\text { corpus callosum into the } 3 r d \\
\text { ventricle }\end{array}$ & Callosal fibers crossing the rostrum & Frontal disconnection syndrome \\
\hline $\begin{array}{l}\text { Posterior transcortical (superior } \\
\text { parietal lobule) } \\
14,42,55,84,117,119\end{array}$ & $\begin{array}{l}\text { Posterior part of the body, atrium, } \\
\& \text { glomus of the choroid plexus }\end{array}$ & $\begin{array}{l}\text { SLF } \|, A F \text {, callosal fibers, \& optic } \\
\text { radiations }\end{array}$ & $\begin{array}{l}\text { Apraxia, acalculia, Gerstmann syndrome, } \\
\text { \& visual field deficits }\end{array}$ \\
\hline $\begin{array}{l}\text { Posterior interhemispheric } \\
\text { transcallosa| } 6,15,29,74,84,119\end{array}$ & $\begin{array}{l}\text { Extending superiorly from the } \\
\text { atrium or splenium of the } \\
\text { corpus callosum }\end{array}$ & Splenium of the corpus callosum & $\begin{array}{l}\text { Auditory or visual disconnection syn- } \\
\text { dromes }\end{array}$ \\
\hline $\begin{array}{l}\text { Posterior interhemispheric } \\
\text { precuneal }^{12,29,60,103,106,118}\end{array}$ & $\begin{array}{l}\text { Medial wall of the atrium \& poste- } \\
\text { rior 3rd ventricle }\end{array}$ & $\begin{array}{l}\text { Forceps major \& sledge runner, } \\
\text { cingulum medially, \&/or SLF I } \\
\text { superiorly }\end{array}$ & $\begin{array}{l}\text { Visual hallucinations in contralateral } \\
\text { visual field, memory disturbance }\end{array}$ \\
\hline $\begin{array}{l}\text { Supracerebellar transtentorial } \\
\text { transcollateral sulcus }{ }^{41,53,54} \\
63,93,124\end{array}$ & $\begin{array}{l}\text { Posteromedial aspect of atrium } \\
\text { \& inferior surface of temporal } \\
\text { horn }\end{array}$ & $\begin{array}{l}\text { Li-Am F, cingulum medially, anterior } \\
\text { part of optic radiations laterally }\end{array}$ & $\begin{array}{l}\text { Differences in social cognition, visual } \\
\text { deficits }\end{array}$ \\
\hline $\begin{array}{l}\text { Paramedian supracerebellar- } \\
\text { transtentorial|72,88,104,107 }\end{array}$ & $\begin{array}{l}\text { Temporal lobe (amygdalohippo- } \\
\text { campectomy) }\end{array}$ & Cingulum, fornix & Behavioral \& cognitive changes \\
\hline $\begin{array}{l}\text { Posterior transtemporal } 7,8,10,13 \text {, } \\
\text { 19-21,26,28,30,55,61,62,67,74,78,86,105,110, } \\
116,124\end{array}$ & $\begin{array}{l}\text { Middle or posterior 3rd of tempo- } \\
\text { ral horn \& atrium }\end{array}$ & $\begin{array}{l}\text { SLF II, AF, MdLF, IFOF, anterior com- } \\
\text { missure, optic radiations }\end{array}$ & $\begin{array}{l}\text { Anomia, phonemic \&/or semantic } \\
\text { paraphasia, visual deficits, Gerstman } \\
\text { syndrome }\end{array}$ \\
\hline Proximal sylvian $6,32,37,114,120$ & $\begin{array}{l}\text { Temporal horn (amygdalohippo- } \\
\text { campectomy) }\end{array}$ & $\begin{array}{l}\text { UF, anterior commissure, Li-Am F, } \\
\text { cingulum, optic radiation }\end{array}$ & Memory deficits, visual deficits \\
\hline Distal sylvian 48,98 & Atrium & $\begin{array}{l}\text { Optic radiations, posterior part of } \\
\text { corona radiata, AF, \& MdLF }\end{array}$ & $\begin{array}{l}\text { Language disorders, auditory disorders, } \\
\text { visual defects }\end{array}$ \\
\hline Subtemporal ${ }^{39,48,53,54,84}$ & $\begin{array}{l}\text { Posterior part of hippocampus \& } \\
\text { inferior part of atrium }\end{array}$ & Li-Am F & Differences in social cognition \\
\hline $\begin{array}{l}\text { Anterior temporal }{ }^{1,5,6,35,73,84,86,108,}, \\
112,124\end{array}$ & Temporal horn & $\begin{array}{l}\text { Optic radiations, AF, IFOF, anterior } \\
\text { commissure, UF, \& ILF }\end{array}$ & $\begin{array}{l}\text { Visual deficits, dysnomia or even apha- } \\
\text { sia, memory deficits }\end{array}$ \\
\hline
\end{tabular}

$\mathrm{AF}=$ arcuate fasciculus; IFOF = inferior frontooccipital fasciculus; ILF = inferior longitudinal fasciculus; Li-Am F = lingular amygdaloidal fasciculus; MdLF = middle longitudinal fasciculus; SLF = superior longitudinal fasciculus; UF = uncinate fasciculus.

to reach the cortex bordering the calcarine sulcus. The posterior part of the optic radiations pursues a horizontal course after departing the LGB to reach the superior part of the calcarine cortex. The posterior and central parts of the optic radiations merge with the sagittal stratum after passing below the inferior limiting sulcus. The anterior part of the optic radiations courses adjacent to the ILF (Figs. 4A-E, 11A, 11B, 11E, and 15A-C).

Removing the sagittal stratum and corona radiata exposes the callosal fibers. We divided the callosal fibers into dorsal and ventral parts. The dorsal fibers pass dorsal from the corpus callosum and connect the paired dorsal parts of the frontal, parietal, and occipital lobes. The fibers crossing the midline in the splenium and connecting the superior halves of the occipital lobes are called the forceps major, which passes along the superior half of the medial wall of the atrium (Table 1). The fibers crossing in the genu of the corpus callosum, called the forceps minor, cover the inferior half of the medial wall of the frontal horn and the rostrum of the callosum covers the inferior wall of the frontal horn (Table 1). The dorsal callosal fibers passing through the body of the corpus callosum cover the superior wall of the body of the lateral ventricle and the superior half of the medial wall of the frontal horn (Table 1). The fibers crossing the midline 

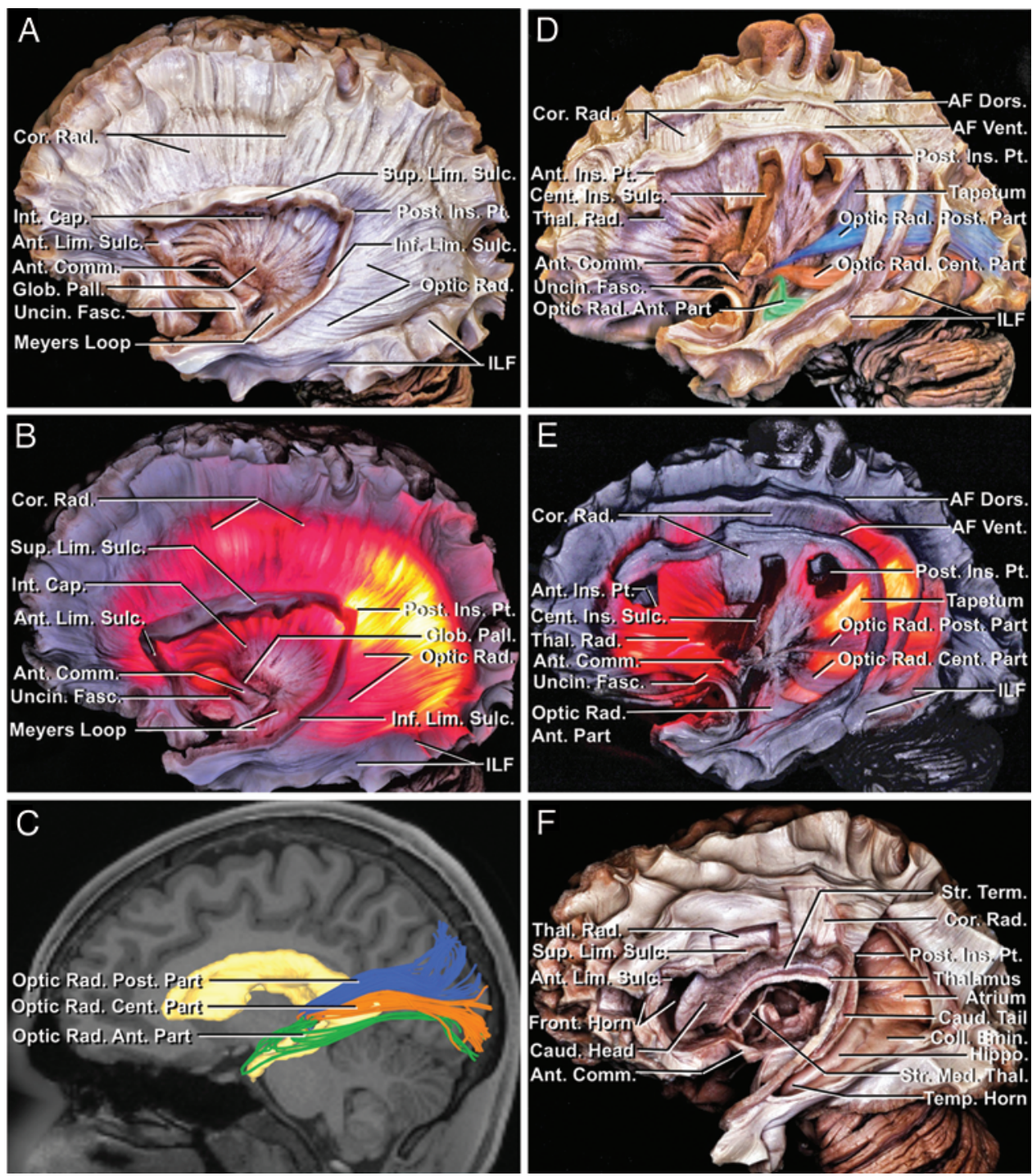

FIG. 4. A: Removing the posterior crus of the anterior commissure exposes Meyer's loop and the optic radiations. The anterior part of the optic radiations has a close relationship with the inferior longitudinal fasciculus, both of which run together from the temporal to the occipital lobe. B: Transillumination shows the relationship of the optic radiations to the temporal horn and atrium. The anterior part of the optic radiations covers the anterior tip of the roof of the temporal horn and runs lateral to the inferior one-third of the temporal horn and inferolateral edge of the atrium. The central part of the optic radiations runs lateral to the middle one-third of the temporal horn and inferior one-third of the atrium and occipital horn. The posterior part of the optic radiations runs lateral to the superior one-third of the temporal horn and middle one-third of the atrium to reach the occipital lobe. C: MR tractography showing the relationship of the optic radiations to the ventricle. The posterior fibers are shown in blue, the central fibers in orange, and the anterior fibers in green. D: Bands of the optic radiations and arcuate fasciculus have been preserved. Removing the optic radiations and parietal part of the corona radiata exposes the tapetal fibers. The tapetal fibers depart from the splenium of the corpus callosum and run laterally and inferiorly on the deep side of the optic radiations at the most superior edge of the atrium, and descend lateral to the roof and lateral wall of the atrium and temporal horn. E: Transillumination shows the relationship between the tapetal fibers and ventricle. The tapetal fibers cover the lateral surface of the atrium and the temporal horn of the lateral ventricle. F: The anterior, superior, and inferior insular sulci and borders of the thalamus have been preserved to show the relationship of the insula to the caudate nucleus, thalamus, and lateral ventricle. Removing the tapetal and occipital fibers exposes the atrium and temporal horn of the lateral ventricle. Removing the internal capsule and caudal segment of the corona radiata fibers exposes the caudate nucleus and stria terminalis. The tail of the caudate nucleus and the stria terminalis course in the roof of the temporal horn, but do not reach its temporal tip. The collateral trigone bulges upward above the collateral sulcus and forms the floor of the atrium of the lateral ventricle. The calcar avis overlies the deep end of the calcarine sulcus, and the bulb of the corpus callosum overlies the fibers of the forceps major in the medial wall of the atrium. The hippocampus lies in the floor of the temporal horn and anterior part of the atrium. $\mathrm{AF}=$ arcuate fasciculus; Ant. = anterior; Cap. = capsule; Caud. = caudate; Cent. = central; Coll. = collateral; Comm. = commissure; Cor. = corona; Dors. = dorsal; Emin. = eminence; Fasc. $=$ fasciculus; Front. = frontal; Glob. = globus; Hippo. = hippocampus; ILF = inferior longitudinal fasciculus; Inf. = inferior; Ins. = insular; Int. = internal; Lim. = limiting; Med. = medullaris; Pall. = pallidus; Post. = posterior; Pt. = point; Rad. = radiata = radiations; Str. = stria; Sulc. = sulcus; Sup. = superior; Temp. $=$ temporal; Term. $=$ terminalis; Thal. $=$ thalami $=$ thalamic; Uncin. $=$ uncinate; Vent. $=$ ventral. 

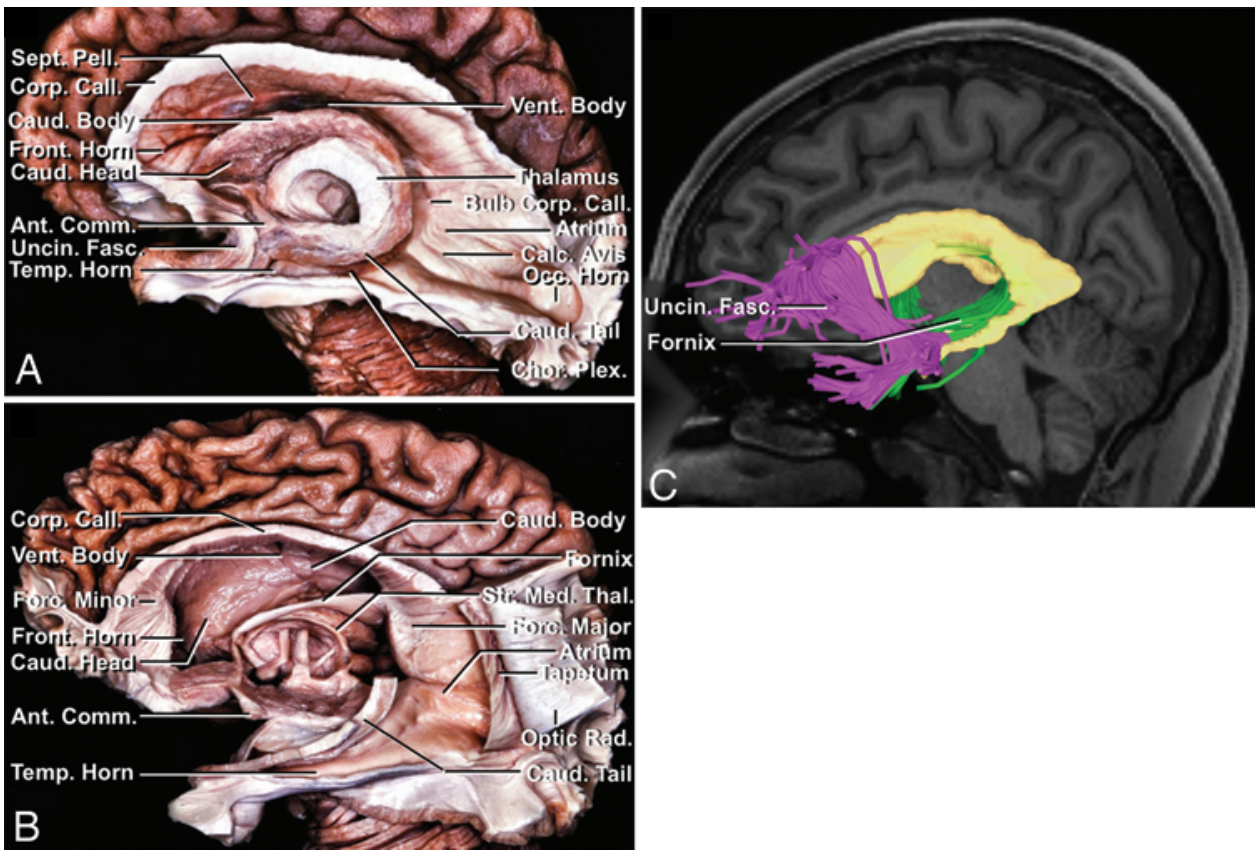

FIG. 5. A: Removing the corona radiata and sagittal stratum exposes the caudate nucleus, corpus callosum, and lateral ventricle. The head of the caudate is positioned in the lateral wall of the frontal horn, the body in the lateral wall of the body of the lateral ventricle and atrium, and the tail in the roof of the temporal horn. The rostrum of the corpus callosum forms the floor and the genu of the corpus callosum forms the anteromedial wall of the frontal horn. The body of the corpus callosum forms the roof of the body of the lateral ventricle. The splenium forms the roof of the atrium. B: Removing the ipsilateral caudate nucleus, ependyma, and septum exposes the fornix, contralateral caudate nucleus, and stria medullaris thalami. The forceps major covers the superior half of the medial wall of the atrium. The body of the fornix forms the medial one-third of the floor of the body of the lateral ventricle. The body of the fornix divides at the superior edge of the anterior commissure. The precommissural fornix continues to the septal area and the postcommissural fornix descends to the mammillary body. C: UF (purple) and fornix (green) in relation to the lateral ventricle on MR tractography. Ant. = anterior; Calc. = calcar; Call. = callosum; Caud. = caudate; Chor. = choroid; Comm. = commissure; Corp. $=$ corpus; Fasc. $=$ fasciculus; Forc. $=$ forceps; Front. $=$ frontal; Med. $=$ medullaris; Occ. $=$ occipital; Pell. = pellucidum; Plex. = plexus; Sept. = septum; Str. = stria; Temp. = temporal; Thal. $=$ thalami; Uncin. $=$ uncinate.

in the dorsal part of the body and isthmus of the corpus callosum at the level of the junction of the paired crura of the fornices connect the superior parts of the frontal and parietal lobes, including the pre- and postcentral gyri, forming the motor and somatosensory strips (Figs. 5A, 7A, 10C, $10 \mathrm{D}$, and $14 \mathrm{~A}-\mathrm{F}){ }^{83,100,116}$ The ventral fibers of the corpus callosum cover the entire superior and lateral wall of the lateral ventricle. The fibers passing through the ventral part of the genu of the corpus callosum cover the anteromedial half of the medial surface of the frontal horn and also connect to the caudate nucleus. The fibers passing through the ventral part of the body cover the roof and superior half of the lateral wall of the body of the ventricle and the superior half of the frontal horn. The fibers passing through the ventral part of the splenium, called the tapetum, cover the superior and lateral wall of the atrium and temporal horn, and they also connect to the caudate nucleus (Figs. 4D, 4E, $5 \mathrm{~B}, 5 \mathrm{C}, 10 \mathrm{E}$, and $14 \mathrm{D}-\mathrm{F}$; Table 2). ${ }^{25,116,117}$ This is the first fiber dissection study describing these fibers interconnecting the paired caudate nuclei, and the first MR tractography showing these intrastriatal callosal fibers.

Removing the callosal fibers, sagittal stratum, and corona radiata opens the superior and lateral surface of the lateral ventricle and exposes the caudate nucleus, stria terminalis, thalamus, septum pellucidum, hippocampus, amygdala, fornix, and choroid plexus of the lateral ventricle (Figs. 4F, 5A, 5B, 11F, 11G, 12A, and 12B). In our dissections the stria terminalis passes along the striathalamic sulcus, which courses between the caudate nucleus and thalamus and along the inferolateral edge of the body of the lateral ventricle, anterolateral edge of the atrium, and roof of the temporal horn as far forward as the temporal tip, and it connects the amygdala with the hypothalamus and septal area (Figs. 4F and 14B; Table 1).

The stria medullaris thalami connects the septal area with the habenula by passing along the dorsomedial surface of the thalamus at the lower edge of the velum interpositum and the floor of the lateral ventricle and at the lower lateral edge of the foramen of Monro near the anterior commissure (Fig. 5B; Table 1).

The fornix runs from the intralimbic gyrus of the hippocampus to the mammillary body and septal area, and can be divided into 5 parts: the fimbria, crus, body, and pre- and postcommissural parts. ${ }^{25}$ The fimbria of the fornix travels on the upper surface of the hippocampus and along the medial part of the floor of the temporal horn. The crus of the fornix courses around the pulvinar in the anterior wall of the atrium. The body of the fornix is located in the medial one-third of the floor of the body of the lateral ventricle, and at the lateral and anterior edge of the 

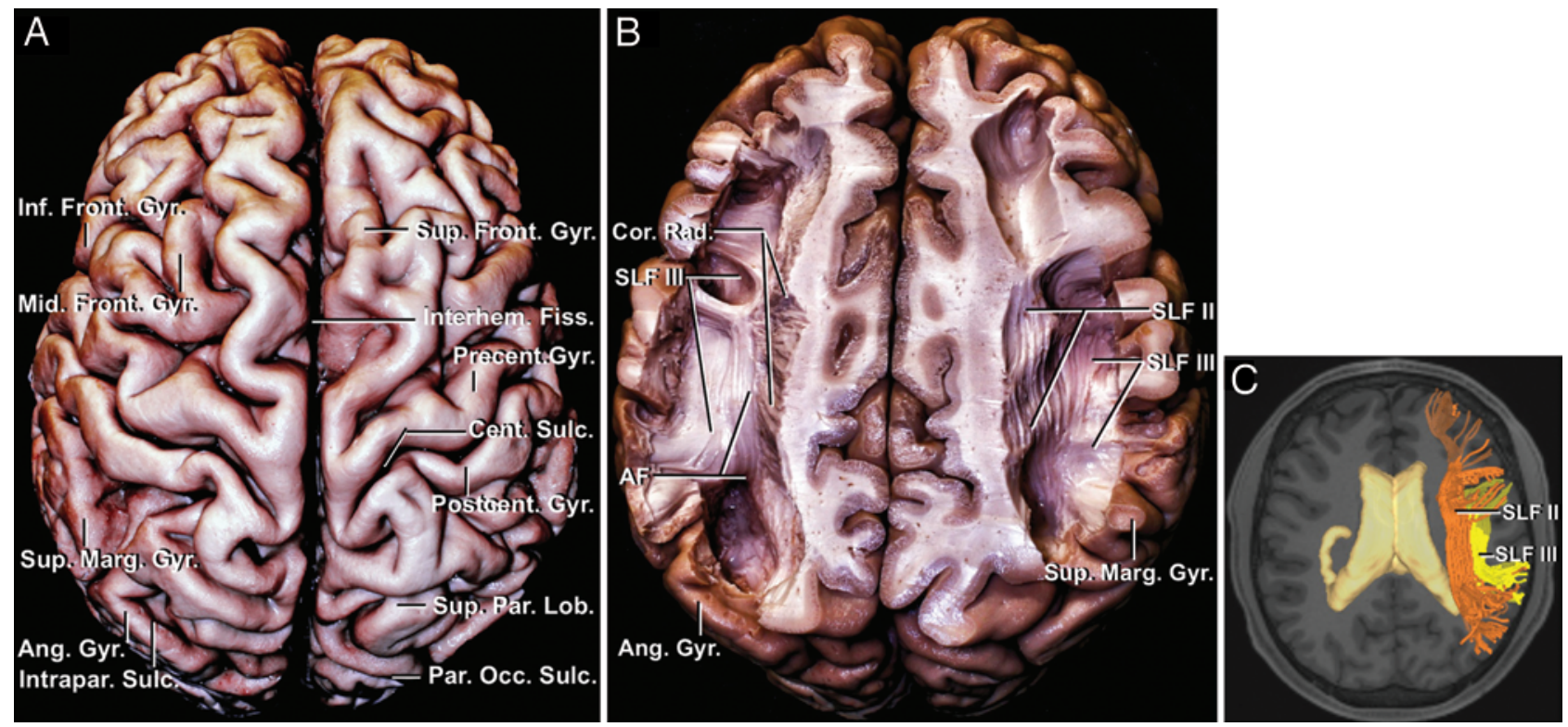

FIG. 6. Fiber dissections from superior to inferior, MR tractography from superior (Figs. 6-10). A: Sulci and gyri on the superior surface of the cerebrum. B: Superior view of the superior longitudinal fasciculus (SLF) II and SLF III. The SLF II runs from the angular gyrus to the mid part of the middle frontal gyrus. The SLF III runs from the supramarginal gyrus to the pars opercularis. C: MR tractography showing the SLF II (orange) and SLF III (yellow) in relation to the lateral ventricle. AF = arcuate fasciculus; Ang. = angular; Cent. = central; Cor. = corona; Fiss. = fissure; Front. = frontal; Gyr. = gyrus; Inf. = inferior; Interhem. = interhemispheric; Intrapar. = intraparietal; Lob. = lobule; Marg. = marginal; Mid. = middle; Par. = parietal; Par. Occ. = parietooccipital; Postcent. $=$ postcentral; Precent. $=$ precentral; Rad. $=$ radiata; SLF $=$ superior longitudinal fasciculus; Sulc. $=$ sulcus; Sup. $=$ superior = supra.

foramen of Monro, where it divides into pre- and postcommissural parts (Figs. 5B, 5C, 10F, and 11G; Table 1).

Removing the cortex and U-fibers of the medial and inferior surface of the hemisphere exposes the cingulum, SLF I, sledge runner fasciculus, lingular amygdaloidal (LiAm) fasciculus, optic radiations, and ILF. The SLF I runs superior to the lateral two-thirds of the roof of the frontal horn, body, and atrium (Table 1). The SLF I connects the superior part of the precuneus to the anterior part of the superior frontal gyrus and courses above, adjacent to, and in the same direction as the superior part of the cingulum (Figs. 7A-D, 13A, 13B, and 13D; Table 2).

The superior part of the cingulum, beginning in the frontal cortex below the genu of the corpus callosum and wrapping around the genu and splenium, courses along the inferior, anterior, and upper surfaces of the frontal horn and superior wall of the body of the lateral ventricle. The inferior part of the cingulum, from the splenium to the anterior part of the parahippocampal gyrus, courses medial to the anterior one-third of the medial wall of the atrium and continues along the medial one-fourth of the floor of the temporal horn under the hippocampus (Table 1). The cingulum connects the subcallosal frontal cortex with the anterior part of the parahippocampal gyrus by coursing around the corpus callosum, narrowing to form an isthmus just behind and below the splenium (Figs. 7A, 7B, 11A, 11B, 11D, 13B, and 13D; Table 2).

The sledge runner fasciculus descends vertically from the posterior part of the precuneus to the lingual gyrus and medial to the posterior two-thirds of the atrium (Tables 1 and 2)..$^{106,113}$ In our dissections the superior one-half of the sledge runner fasciculus passes medial to the forceps major
(Fig. 13B, 13C, and 13E). To our knowledge, this is the first time the sledge runner fasciculus has been reported in both fiber dissections and on MR tractography in a single study.

The Li-Am fasciculus connects the amygdala to the lingual gyrus and passes between the cingulum and optic radiations covering the middle one-half of the floor of the temporal horn and medial two-thirds of the floor of the atrium (Fig. 11A, 11B, 11D, and 11E; Tables 1 and 2). ${ }^{53,54}$ To our knowledge, this is the first report that shows the Li-Am fasciculus in both MR tractography and fiber dissection.

\section{Discussion}

The surgical treatment of lateral ventricular lesions is made challenging by the complicated relationships between the tracts in the depth of the brain and the ventricles, which has led to the search for new, minimally invasive approaches to prevent causing damage. $9,16,41,45,48,55,57,59,75,84,94,125$ Understanding the periventricular white matter tracts is helpful not only in defining more precise surgical strategies, but also in clarifying the symptoms of and appropriate treatment for patients with hydrocephalus and periventricular lesions. . $^{11,18,36,38,40,47,50,52,58,65,66,76,80,101}$

This study examines the tracts at risk in the 3 surgical routes-anterior, posterior, and lateral-to the lateral ventricle. The anterior approaches include the anterior interhemispheric transcallosal, anterior frontal transcortical, and anterior frontal interhemispheric transrostral; the posterior approaches include the posterior transcortical (superior parietal lobule), posterior interhemispheric transcallosal, posterior interhemispheric precuneal, supracere- 

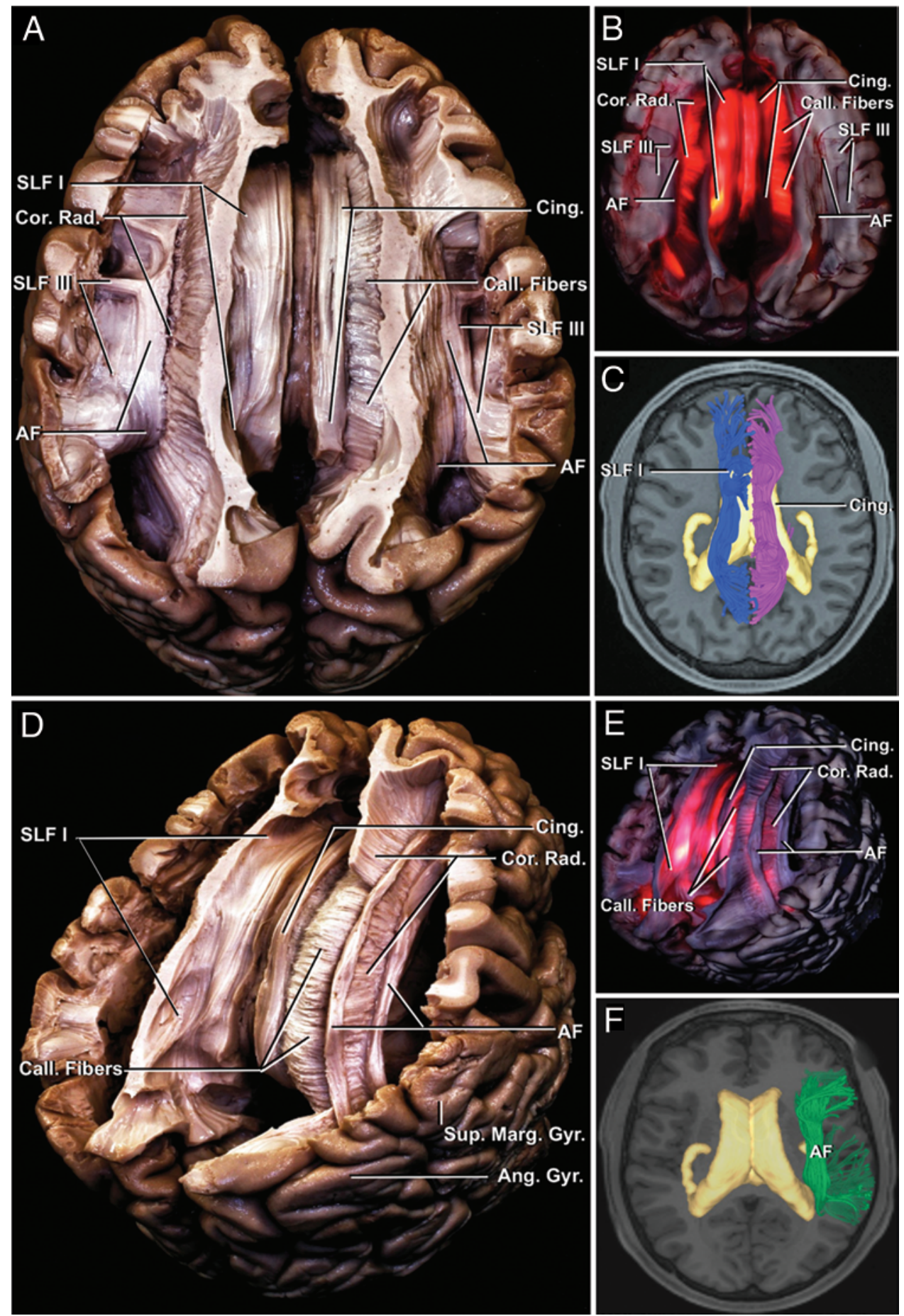

FIG. 7. A: The superior longitudinal fasciculus (SLF) I runs from the precuneus to the anterior part of the superior frontal gyrus, and medial to the callosal fibers. The cingulum runs just above the corpus callosum and below the SLF I, and then inferiorly around the splenium and genu. B: Transillumination showing the cingulum and SLF I running superior to the atrium, body, and frontal horn. C: MR tractography showing the SLF I (blue) and cingulum (purple) in relation to the lateral ventricle. D: Right oblique superior view of the arcuate fasciculus $(A F)$, which runs from the middle part of the inferior and middle frontal gyri to the temporal lobe and deep to the angular and supramarginal gyri. E: Transillumination showing the AF running lateral to the atrium, body, and frontal horn. F: MR tractography showing the AF (green) in relation to the lateral ventricle. $A F=$ arcuate fasciculus; Ang. = angular; Call. = callosal; Cing. = cingulum; Cor. = corona; Gyr. = gyrus; Marg. = marginal; Rad. = radiata; SLF = superior longitudinal fasciculus; Sup. $=$ supra. 

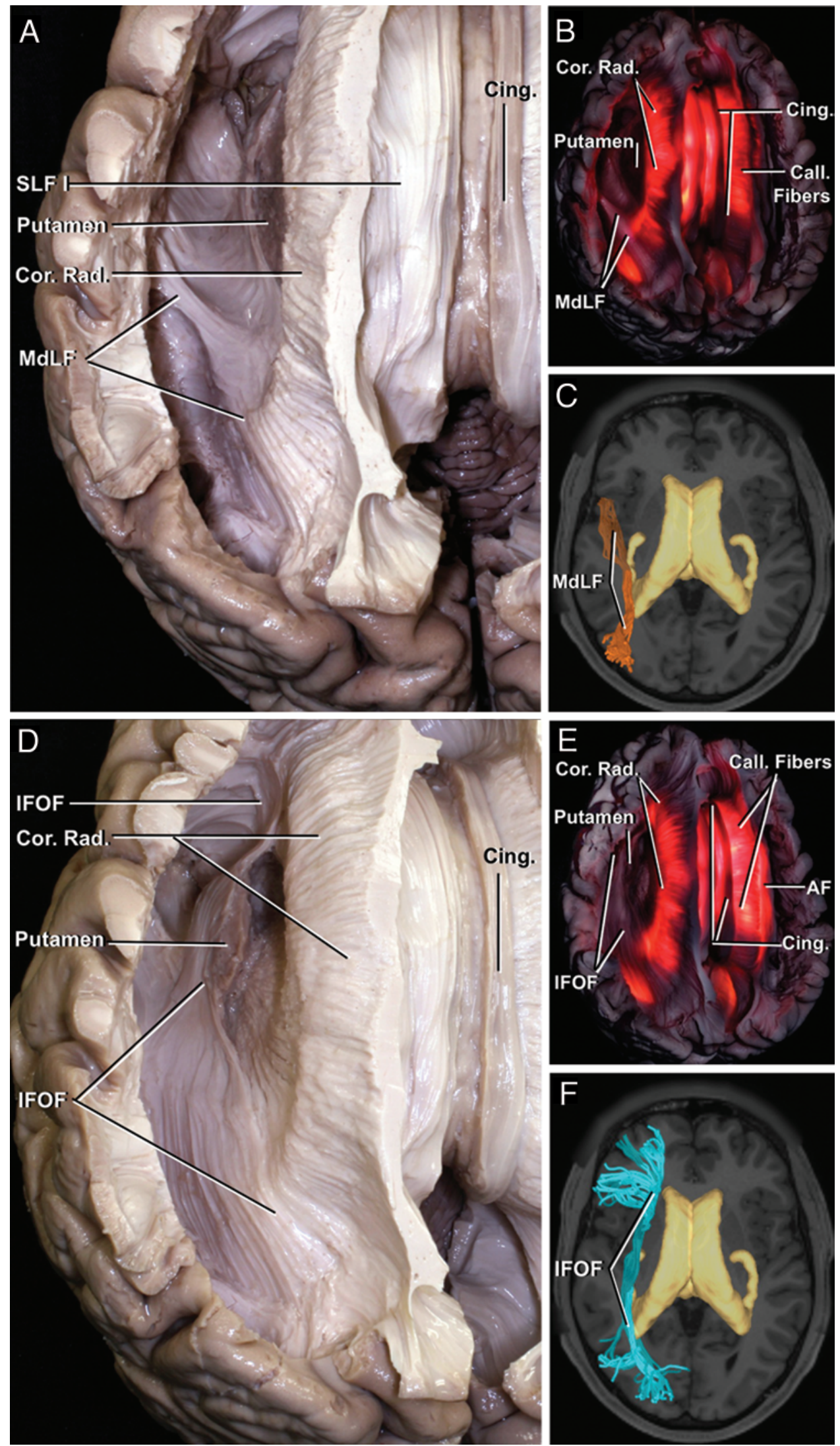

FIG. 8. A: Superior view of the middle longitudinal fasciculus (MdLF), which runs from the superior temporal gyrus to the angular gyrus. B: Transillumination showing the MdLF running lateral to the superior part of the temporal horn and middle one-third of the atrium. C: MR tractography showing the MdLF (orange) in relation to the lateral ventricle. D: Left oblique superior view of the inferior frontooccipital fasciculus (IFOF), which runs from the anterior part of the middle and inferior frontal gyri and across the limen insula to reach the temporal and occipital lobes. E: Transillumination showing the posterior part of the IFOF running lateral to the temporal horn and the inferior two-thirds of the atrium to reach the occipital lobe. The anterior part of the IFOF runs lateral to the inferior two-thirds of the frontal horn. F: MR tractography showing the relationship of the IFOF (aqua) to the lateral ventricle. $\mathrm{AF}=$ arcuate fasciculus; Call. = callosal; Cing. = cingulum; Cor. = corona; IFOF = inferior frontooccipital fasciculus; $M d L F=$ middle longitudinal fasciculus; Rad. = radiata; SLF = superior longitudinal fasciculus. 
bellar-transtentorial transcollateral sulcus, and paramedian supracerebellar-transtentorial; and the lateral approaches include the anterior temporal lobectomy, distal or proximal transsylvian, and trans- or subtemporal (Table 3). ${ }^{48,84}$ The tracts affected by hydrocephalus are also discussed.

\section{Operative Approaches to the Lateral Ventricle \\ Anterior Approaches}

Anterior Interhemispheric Transcallosal Approach. This approach, used to access lesions located within the frontal horn and body of the lateral ventricle and third ventricle, and directed through an incision in the genu or body of the corpus callosum, may result in a frontal disconnection syndrome that includes deficits of long-term visual and verbal memory, dysexecutive cognitive and behavioral syndrome, and disturbances in interhemispheric transfer of motor learning (Fig. 16). ${ }^{81}$ Memory deficits can also appear as a result of forniceal damage. ${ }^{6}$ Our dissections revealed a connection between the paired caudate nuclei passing through the ventral part of the corpus callosum, which could be damaged in this approach, with resulting loss of executive and goal-directed actions with dysexecutive cognitive and behavioral syndrome (Tables 1-3). ${ }^{34,85,90}$

Anterior Frontal Transcortical Approach. This approach passes through the mid part of the middle frontal gyrus to the frontal horn, anterior part of the body, and anterior or superior part of the third ventricle, and may be combined with opening the choroidal fissure (Fig. 16; Table 3). ${ }^{22,84,119}$ Although previous studies reported postoperative hemiparesis in the anterior transcallosal and anterior transcortical approaches, Szmuda et al. found only a $1 \%$ incidence of damage to the upper motor axons resulting from the transcortical approach. ${ }^{95}$ Based on these findings, postoperative hemiparesis was attributed to indirect damage of the thalamus, basal ganglia, internal capsule, motor cortex, supplementary motor area, or corticospinal tract, caused by compression from the tumor, perioperative retraction, or damage to venous drainage or arterial supply. ${ }^{95}$ The anterior transcortical approach can result in speech and facial apraxia, neuropsychological deficit, memory dysfunction, agraphia, or spatial neglect (Table 3), 22,70,77,82,95,119 which, based on our dissections, may damage the anterior part of the SLF II, AF, IFOF, and corona radiata (claustrocortical and frontopontine fibers, superior frontal thalamic radiations), and the ventral callosal fibers in the genu and body (Table 3). Extending the approach through the superior frontal gyrus may damage the anteromedial part of the SLF I, the anterior part of the cingulum, and the dorsal part of the genu and body of the corpus callosum. The SLF is a 3-part frontoparietal connection pathway that forms the ventral visuospatial pathway with the IFOF and ILF and also includes part of the AF and cingulum. , $14,42,68,99^{\text {Dys- }}$ function of spatial awareness can appear with damage to the SLF II and III, especially in the nondominant hemisphere (Table 2). The AF is the largest and best-known tract of the dorsal language network and if damaged may be associated with deficits of phonological, lexical, and semantic language processing, and visuospatial processing (Table 3). $., 78,88,111$ Damage to the IFOF, a part of the ventral language pathway, and the AF, a part of the dorsal lan- guage pathway, may also be associated with language disorders. ${ }^{86,105}$ Limbic system dysfunction, including cognitive decline and personality changes, can appear with damage to the frontal thalamic radiations and cingulum (Table 2). ${ }^{70}$

Frontal Interhemispheric Transrostral Approach. This approach, directed through the rostrum of the corpus callosum to lesions involving the floor and lower part of the anterior wall of the frontal horn or extending from the rostrum of the corpus callosum into the third ventricle, may damage the callosal fibers passing through the rostrum, with a resulting frontal disconnection syndrome similar to that seen in the anterior transcallosal approach (Fig. 16; Tables 1 and 3). ${ }^{81,84}$

\section{Posterior Approaches}

Superior Parietal Lobule Approach. This is the most common approach to lesions in the posterior part of the body and atrium of and glomus of the choroid plexus (Fig. 16). ${ }^{22,84}$ In this approach a cortical incision is made along the superior parietal lobule to reach the junction of the body and atrium of the lateral ventricle. The incision crosses the ventral callosal fibers (tapetum) connecting the paired temporal, posterior parietal, and anterior occipital lobes, and the dorsal callosal fibers (forceps major) connecting the superior part of the parietal lobes resulting in auditory or visual disconnection syndromes such as hemifacial metamorphosia, tactile and visual anomia, auditory extinction, and visual hallucinations. Inferior homonymous quadrantanopia may result from damage to the posterior part of the optic radiations, and apraxia, acalculia, and Gerstmann syndrome from the damage to the SLF II or AF if the approach deviates laterally (Tables 2 and 3).,14,42,55,117,119

Posterior Interhemispheric Transcallosal Approach. This approach accesses lesions that extend superiorly from the atrium or the splenium (Fig. 16). ${ }^{48,84,119}$ It crosses the splenium of the corpus callosum, damaging the dorsal callosal fibers that connect the occipital lobes and the ventral callosal fibers that connect the parietal and temporal lobes, potentially causing auditory or visual disconnection syndromes and alexia without agraphia, frequently accompanied by a right homonymous hemianopsia (Tables 2 and 3). $6,15,29,74,119$

Posterior Interhemispheric Precuneal Approach. This approach, directed through the precuneus just anterior to the parietooccipital sulcus to reach the atrium, can be used for lesions involving the medial wall of the trigone and posterior third ventricle, and it avoids damage to the splenium and optic radiations, as described by Yaşargil (Fig. 16; Table 3). ${ }^{118}$ In our dissections and MR tractography, the forceps major and sledge runner fasciculus appear to be at risk in this approach. If the route deviates medially or superiorly, the cingulum or SLF I, respectively, may be damaged. Recent studies demonstrated that the precuneus, together with the lateral posterior parietal cortex, may play an important role in visuospatial attention, control of the dorsal attention network, retrieving visual, auditory, and recent memory, self-processing, and consciousness..$^{12,57,60,103}$ The sledge runner fasciculus, connecting the precuneus and the lingual gyrus, may function in the integration of visual stimuli from the inferior portion of the visual field 

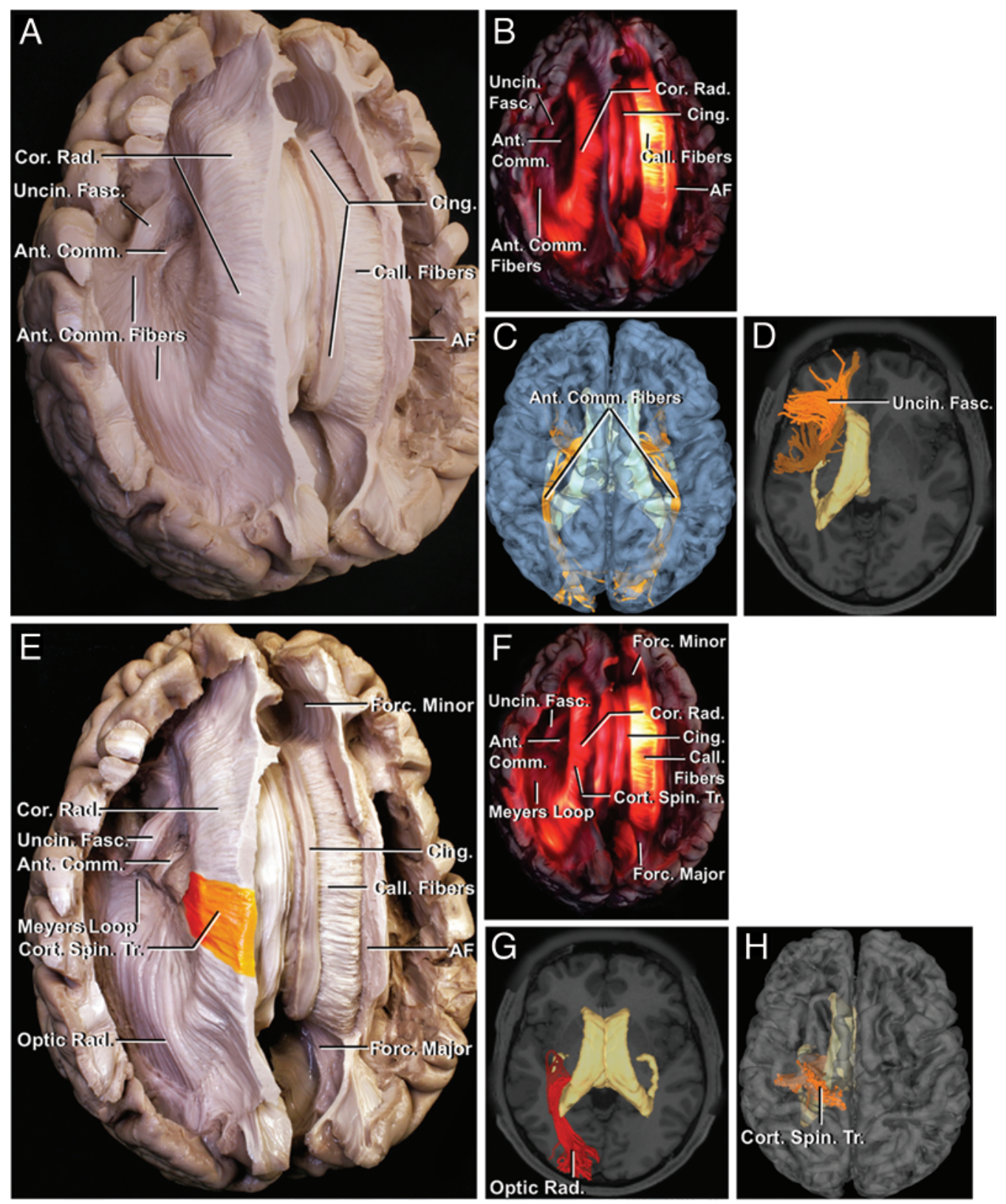

FIG. 9. A: Oblique superior view of the anterior commissure, which passes deep to the insula and connects the occipital and temporal lobes, and the uncinate fasciculus (UF), which connects the frontal and temporal lobes. B: Transillumination showing the occipital and temporal extensions of the anterior commissure running lateral to the temporal horn and inferior two-thirds of the atrium. C: MR tractography showing the relationship of the anterior commissure (orange) with the lateral ventricle. D: MR tractography showing the relationship of the UF (orange) with the lateral ventricle. E: Left superooblique view of the optic radiations, which emerge from the lateral geniculate body and run to the temporal and occipital lobes. The corticospinal tract has been colored in orange. F: Transillumination shows the optic radiation fibers running lateral to the temporal horn and inferior two-thirds of the atrium of the lateral ventricle. Meyer's loop covers the temporal horn. G: MR tractography showing the optic radiations $(r e d)$ in relationship to the lateral ventricle. $\mathrm{H}$ : MR tractography showing the corticospinal tract (orange) in relation to the lateral ventricle. $\mathrm{AF}=$ arcuate fasciculus; Ant. = anterior; Call. = callosal; Cing. = cingulum; Comm. = commissure; Cor. = corona; Cort. = cortico; Forc. $=$ forceps; Rad. $=$ radiata $=$ radiations; Spin. $=$ spinal; Tr. $=$ tract.

and parahippocampal areas involved in the recognition of places and, if damaged, may result in an inability to recognize places (Table 2). ${ }^{106}$ Ghosh et al. described a patient with a right retrosplenial infarct that caused visual hallucinations in the contralateral visual field. ${ }^{29}$
Supracerebellar-Transtentorial Transcollateral Sulcus. This approach to the atrium and temporal horn of the lateral ventricle was first described by Izci et al. in a cadaveric model, before its use in patients (Fig. 16; Table 3). ${ }^{41,63}$ The approach requires an incision in the tentorium 

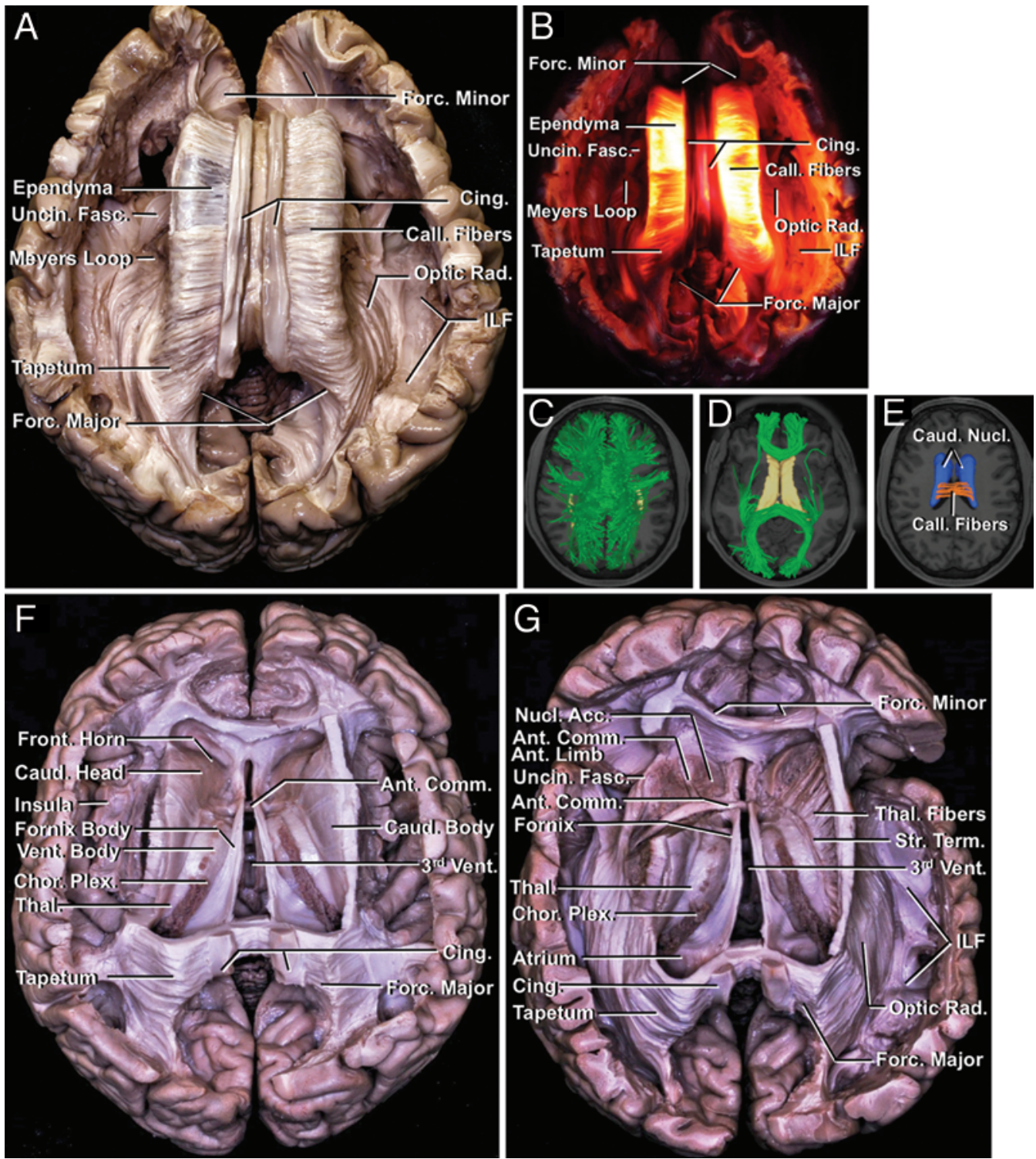

FIG. 10. A: Superior view of the callosal fibers. The fibers passing through the ventral part of the body and genu of the corpus callosum and tapetum connect the paired caudate nuclei across the midline. B: Transillumination shows the relationship of the callosal fibers with the ventricle. The forceps minor runs medial to the frontal horn to reach the anterior part of the frontal lobe. The forceps major runs medial to the superior half of the atrium to reach the posterior part of the occipital lobe. Tapetal fibers form the ventral part of the splenium and cover the lateral wall of the atrium and temporal horn. The ventral fibers of the body of the corpus callosum cover the superior and half of the lateral wall of the body. The ventral fibers of the genu of corpus callosum cover the superior and lateral wall of the frontal horn. C: MR tractography showing the callosal fibers (green) in relation to the lateral ventricle. D: MR tractography showing the tapetum, forceps major, and forceps minor (green) connecting the paired caudate nuclei. E: MR tractography showing the ventral callosal fibers (orange) in relation to the caudate nucleus (blue). F: Superior view of the body and frontal horn of the lateral ventricle. The caudate nucleus is located lateral to the inferior two-thirds of the body of the lateral ventricle and the posterior half of the frontal horn. The body of the fornix is located in the medial part and the thalamus in the lateral part of the floor of the body of the lateral ventricle. G: Superior view of the thalamic radiations, anterior commissure, and nucleus accumbens. The thalamic radiations emerge from the thalamus and course lateral to the caudate nucleus. The body of the anterior commissure crosses the midline just anterior to the foramen of Monro and divides into anterior and posterior crura at the level of the lateral edge of the frontal horn. The anterior crus of the anterior commissure follows an anterior course to the medial orbitofrontal area. The posterior crus of the anterior commissure follows a superolateral course to the temporal lobe. The nucleus accumbens is located below the head of the caudate nucleus, medial to the anterior crus of the anterior commissure, and anterior to the body of the anterior commissure. Acc. = accumbens; Ant. = anterior; Call. = callosal; Caud. = caudate; Chor. = choroid; Cing. = cingulum; Comm. = commissure; Fasc. $=$ fasciculus; Forc. $=$ forceps; Front. $=$ frontal; ILF $=$ inferior longitudinal fasciculus; Nucl. = nucleus; Plex. = plexus; Rad. = radiations; Str. = stria; Term. = terminalis; Thal. $=$ thalamic $=$ thalamus; Uncin. = uncinate; Vent. $=$ ventral $=$ ventricle 

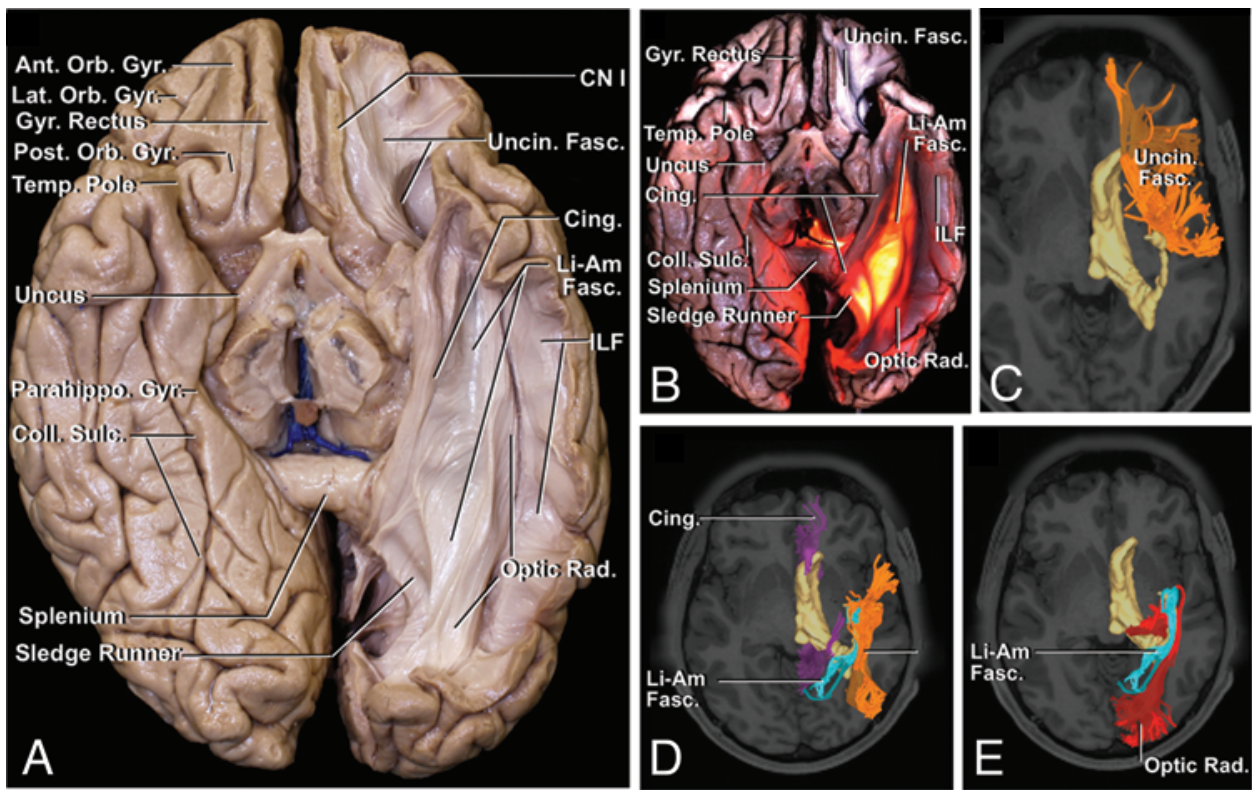

FIG. 11. Fiber dissections from inferior to superior, MR tractography from inferior. A: Sulci and gyri on the inferior surface of the brain. Removing the cortex and U-fibers of the left inferior surface exposes the anterior part of the uncinate fasciculus (UF), inferior longitudinal fasciculus (ILF), cingulum, sledge runner fasciculus,

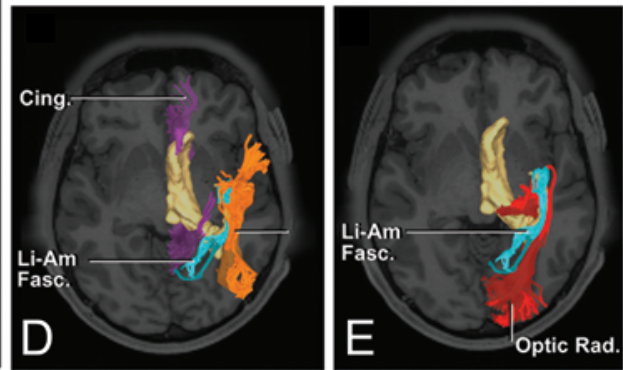
and optic radiations. After emerging from the lateral geniculate body, the anterior part of the optic radiations forms Meyer's loop and courses posteriorly to reach the inferior occipital lobe. The lingular amygdaloidal (Li-Am) fasciculus runs from the amygdala to the lingula, under the
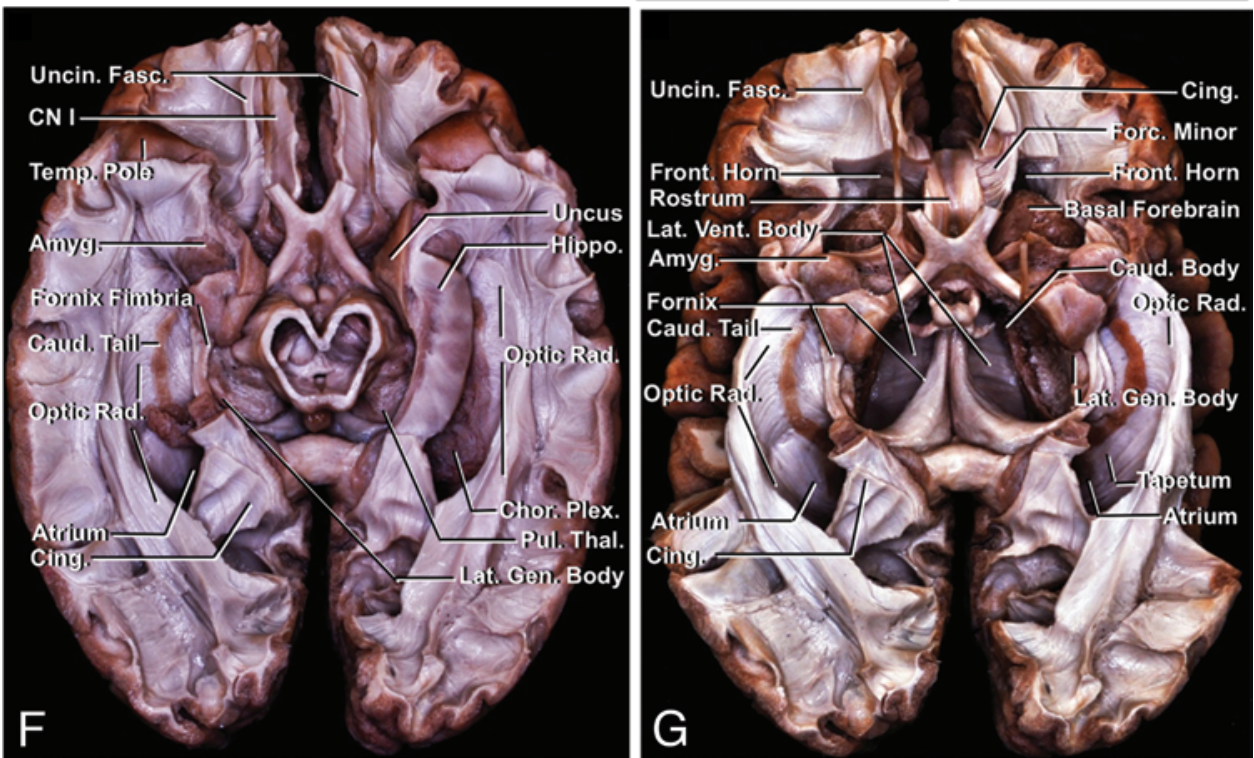
collateral sulcus, and between the cingulum and optic radiations. B: Transillumination shows the relationship of the anterior part of the ILF, cingulum, sledge runner fasciculus, Li-Am fasciculus, and optic radiations with the lower surface of the temporal horn and atrium. The anterior part of the UF passes below the inferior surface of the frontal horn. The cingulum passes below the medial fourth of the floor of the temporal horn. The ILF runs lateral and inferior to the temporal horn and the atrium. The sledge runner courses medial to the atrium.

The Li-Am fibers course below the middle half of the floor of the temporal horn and medial two-thirds of the floor of the atrium. The anterior part of the optic radiations runs below the lateral one-fourth of the floor of the temporal horn and lateral one-third of the floor of the atrium. C: MR tractography showing the relationship of the UF (orange) with the lateral ventricle. D: MR tractography showing the relationships of the cingulum (purple), ILF (orange), and sledge runner fasciculus (aqua) with the lateral ventricle. E: MR tractography showing the optic radiations (red) and Li-Am (aqua) fibers in relation to the lateral ventricle. F: Removing the Li-Am fibers and the temporal part of the cingulum and ependyma of the temporal horn exposes the hippocampus, choroid plexus, amygdala, and optic radiations. The hippocampus is located on the medial half of the floor of the temporal horn. The anterior part of the optic radiations covers a quarter of the floor and the anterior part of the roof of the temporal horn, and inferior one-third of the atrium. The central part of the optic radiations runs lateral to the middle one-third of the temporal horn and inferior one-third of the atrium of the lateral ventricle. The posterior part of the optic radiations runs lateral to the superior one-third of the temporal horn and middle one-third of the atrium of the lateral ventricle. The amygdala is located in the anteromedial part of the anterior wall of the temporal horn adjacent to the hippocampal head. Removing the body of the hippocampus exposes the fimbria of the fornix, lateral geniculate body, tail of the caudate nucleus, and the beginning part of the optic radiation. The fimbria of the fornix emerges from the intralimbic gyrus and just above the hippocampus. The tail of the caudate nucleus runs along the medial one-third of the roof of the temporal horn of the lateral ventricle, and below the optic radiations. G: Removing the brainstem and thalamus exposes the fornix, caudate body, and lateral ventricle. The body of the fornix forms the medial one-third of the floor and the caudate body is located in the lateral wall of the body of the lateral ventricle. Removing the frontal part of the UF exposes the frontal horn of the lateral ventricle and the large nuclear mass below the putamen and head of the caudate nucleus referred to as the basal forebrain. The basal forebrain is located inferior to the posterior half of the frontal horn . Amyg. = amygdala; Ant. = anterior; Caud. = caudate; Chor. = choroid; Cing. = cingulum; $\mathrm{CN}=$ cranial nerve; Coll. = collateral; Fasc. $=$ fasciculus; Forc. = forceps; Front. = frontal; Gen. = geniculate; Gyr. = gyrus; Hippo. = hippocampus; ILF = inferior longitudinal fasciculus; Lat. = lateral; Li-Am = lingular amygdaloidal; Orb. = orbital; Parahippo, parahippocampal; Plex. = plexus; Post. = posterior; Pul. = pulvinar; Rad. = radiations; Sulc. = sulcus; Temp. $=$ temporal; Thal. $=$ thalami; Uncin. $=$ uncinate; Vent. = ventricle 


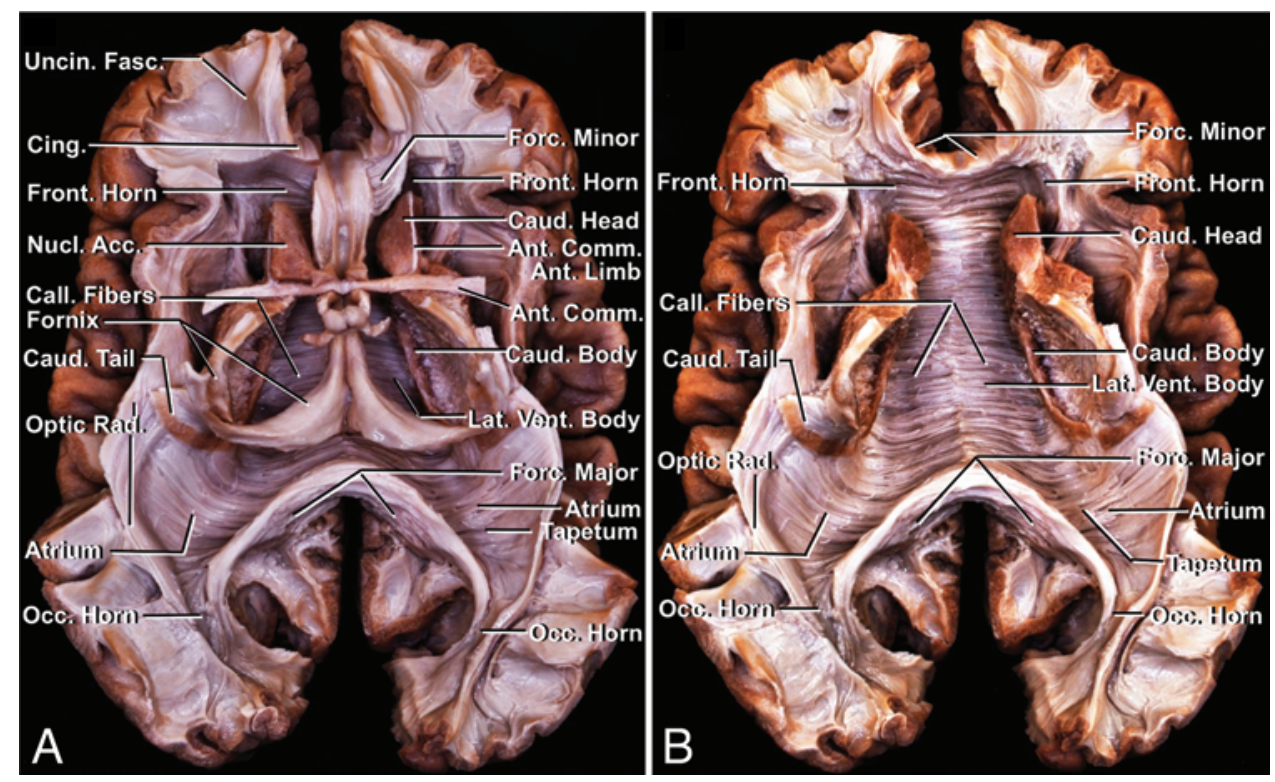

FIG. 12. A: Removing the posterior part of the cingulum exposes the forceps major and tapetal fibers. The forceps major connects the occipital lobes and covers the superior half of the medial surface of the atrium. The tapetal fibers cover the superior and lateral wall of the atrium and temporal horn. Removing the optic tract exposes the body of the anterior commissure crossing the midline just anterior to the foramen of Monro. B: Removing the fornix and anterior commissure exposes the dorsal part of the callosal fibers, which connect the paired caudate nuclei. The dorsal part of the callosal fibers covers the superior and lateral surface of the lateral ventricle above the level of the caudate nucleus. Acc. = accumbens; Ant. = anterior; Call. = callosal; Caud. = caudate; Cing. = cingulum; Comm. = commissure; Fasc. = fasciculus; Forc. = forceps; Front. = frontal; Lat. = lateral; Nucl. = nucleus; Occ. = occipital; Rad. = radiations; Uncin. = uncinate; Vent. = ventricle.

and the collateral sulcus to reach the atrium and temporal horn, and it provides access to lesions in the posteromedial aspect of the atrium and inferior surface of the temporal horn. It has been claimed that there are no white matter tracts along this route. ${ }^{41,63}$ However, the floor of the atrium and temporal horn are covered by short association fibers and the Li-Am fasciculus, optic radiations, and cingulum fibers, with the short association fibers and the Li-Am fasciculus appearing, in this study, to have the greatest risk of damage in this approach (Table 3). To our knowledge, this is the first study to describe the relationships of the Li-Am fasciculus to other white matter tracts (cingulum, optic radiations, ILF, sledge runner, and short association fibers), and to the atrium and temporal horn of the lateral ventricle by fiber dissection technique correlated with MR tractography imaging. The Li-Am fasciculus appears to be distinct from the ILF, because the optic radiations form a partition between them. The Li-Am fasciculus, connecting the limbic and visual systems, has been linked to developmental and individual differences in social cognition, and damage to this structure has been implicated in the propagation of occipital lobe epilepsy and deterioration of social cognition. ${ }^{53,54,93}$ Damage to the anterior part of the optic radiations in this approach may result in superior homonymous quadrantanopsia. ${ }^{124}$

Paramedian Supracerebellar-Transtentorial Approach. This approach was initially described by Voigt and Yaşargil for reaching lesions located on the mediobasal surface of the temporal lobe, and it was recently modified by Türe et al. to provide an alternate route for amygdalohippocampec- tomy in patients with epilepsy resulting from hippocampal sclerosis to avoid damaging the optic radiations (Fig. 16; Table 3). ${ }^{104,107}$ This approach requires a parahippocampal gyrus incision to reach the hippocampus and amygdala, which can damage the cingulum, fornix, and Li-Am fasciculus and may cause limbic system dysfunction with behavioral and cognitive changes (Table 3). 53,54,72,88

\section{Lateral Approaches}

Anterior Temporal Lobectomy. This lobectomy, which involves en bloc removal of the hippocampus and amygdala through a lateral temporal incision beginning approximately $5.5 \mathrm{~cm}$ from the temporal tip on the nondominant hemisphere and $4.5 \mathrm{~cm}$ from the temporal tip on the dominant side ${ }^{84,124}$ may damage the anterior part of the optic radiations, resulting in a superior homonymous quadrantanopia in $48 \%-100 \%$ of patients (Fig. 16; Table 3). ${ }^{1,5,73,112}$ The degree of visual field defect can be correlated with the size of the temporal lobe resection. ${ }^{5,73}$ Dominant-hemisphere temporal lobe resection may also cause transitory postoperative memory deficits including dysnomia or even aphasia due to damage of the AF, IFOF, UF, or ILF (Tables 1 and 2). . $35,86,108,124$

A modification of the transtemporal approach that includes a cortical incision through the posterior part of the middle temporal gyrus to reach lesions in the posterior one-third of the temporal horn and the atrium carries a high risk of visual and language disconnection syndromes if the AF and optic radiation are damaged (Fig. 16; Tables 1 and 2). ${ }^{55,74} \mathrm{~A}$ previous study from our laboratory divided the AF into dorsal and ventral parts. ${ }^{116}$ The ventral part 


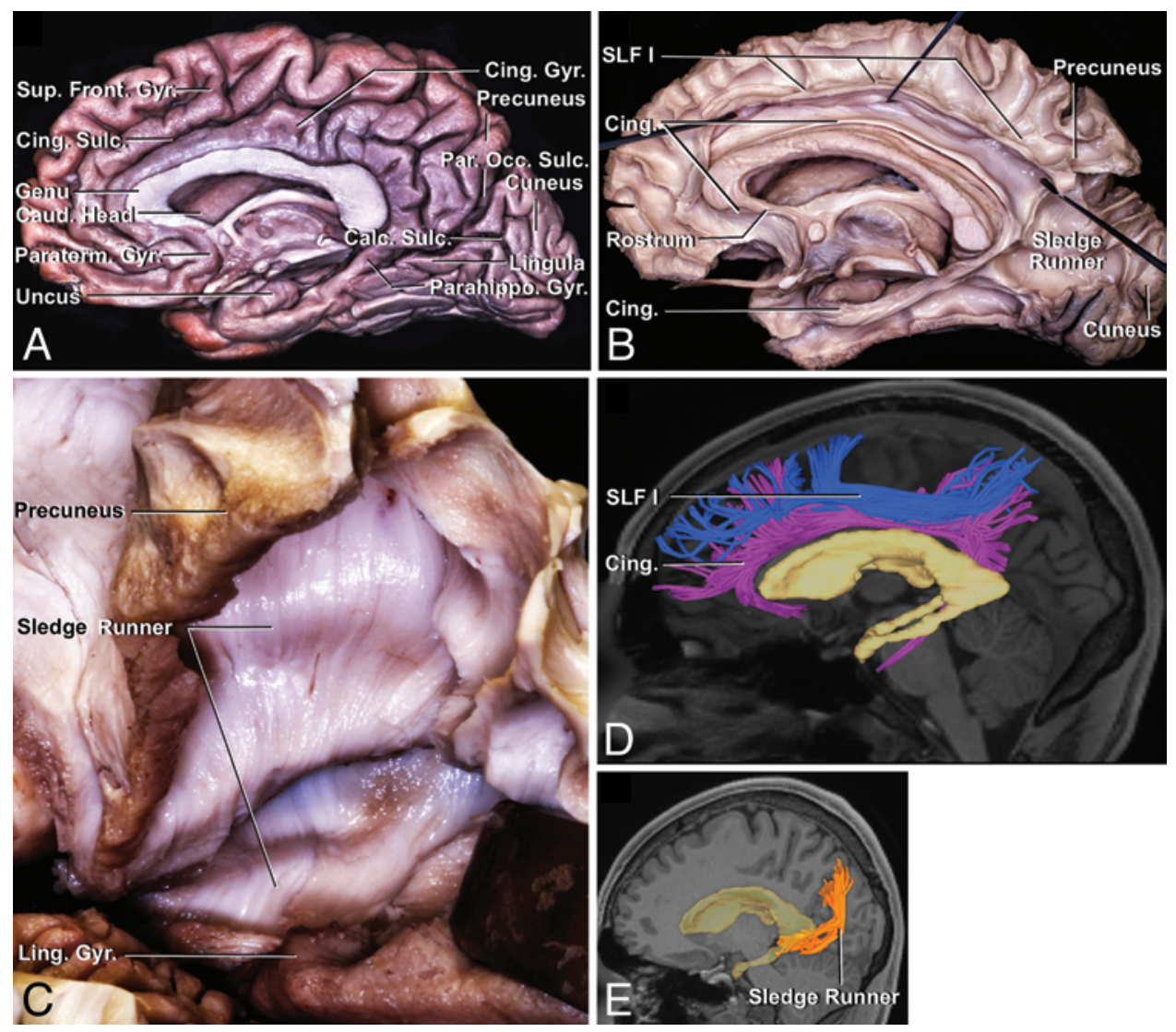

FIG. 13. Fiber dissection from medial to lateral, MR tractography from medial. A: Sulci and gyri of the medial surface of the right hemisphere. B: Removing the medial cortex exposes the superior longitudinal fasciculus (SLF) I, cingulum, and sledge runner fasciculus. The SLF I runs above the cingulum and superior to the lateral two-thirds of the frontal horn, body, and atrium. In this dissection, the SLF I has been retracted superiorly to show the cingulum. The anterior part of the cingulum lies superomedial to the frontal horn and turns downward to course anterior and inferior to the frontal horn. The posterior part of the cingulum is positioned medial to the anterior one-third of the medial wall of the atrium and continues below the medial quarter of the floor of the temporal horn. The sledge runner fasciculus runs from the precuneus to the lingula, beneath the calcarine sulcus, just behind the cingulum and medial to the posterior two-thirds of the medial wall of the atrium. C: Enlarged view of sledge runner fasciculus. D: MR tractography of the cingulum (purple) and SLF I (blue) fibers in relation to the lateral ventricle. E: MR tractography of the sledge runner fasciculus (orange) in relation to the lateral ventricle. Calc. = calcarine; Caud. = caudate; Cing. = cingulate = cingulum; Front. = frontal; Gyr. = gyrus; Ling. = lingual; Par. Occ. = parietooccipital; Parahippo. = parahippocampal; Paraterm. = paraterminal; Sulc. $=$ sulcus; Sup. $=$ superior.

courses from the middle and posterior portions of the superior and middle temporal gyri to the pars opercularis or triangularis, passing deep to the supramarginal gyrus. The dorsal part passes from the middle and inferior temporal gyri to the posterior part of the middle frontal gyrus, passing deep to the angular gyrus. ${ }^{116}$ This classification is also based on the functions of the 2 parts of the AF revealed in lesion-task-based, electrical stimulation, and direct neuroimaging studies. ${ }^{8,10,13,19-21,26,30,62,78,105}$ Combining these studies with our findings makes it appear that the ventral segment of the AF is associated with phonological language processing, and the dorsal segment is associated with lexical and semantic language processing (Table 2). ${ }^{8,10,13,19-}$ $21,26,30,62,78,105$ Damage to the mid and posterior segments of the ventral part of the AF can result in anomia and phonemic paraphasia, while damage to the dorsal part of the AF can result in sematic paraphasia (Table 2). ${ }^{13,62}$ The posterior part of the IFOF lies under the middle and superior temporal gyri and is at risk in the transtemporal approach. Stimulation of the IFOF has induced transient semantic paraphasia with a high level of reproducibility,,$^{13}$ and this along with anatomical studies has suggested that the IFOF has an important role in the language networks, particularly in semantic processing (Tables 2 and 3). ${ }^{13,62,86,105}$ The central and posterior parts of the optic radiations are also at risk in the modified transtemporal approach. Injury to the posterior part of the optic radiations may cause homonymous inferior quadrantanopia and injury to the central part of the optic radiation fibers may cause macular visual defects. ${ }^{7,28,124}$ While the function of the MdLF is still unclear, Makris et al. suggested that by connecting the superior temporal gyrus with the angular and superior occipital gyri it plays a role in cognitive functions in the right hemisphere and language in the left hemisphere (Table 2).61,67,110 A cortical incision that extends into the dominant angular gyrus may also cause Gerstmann syndrome (right-left 

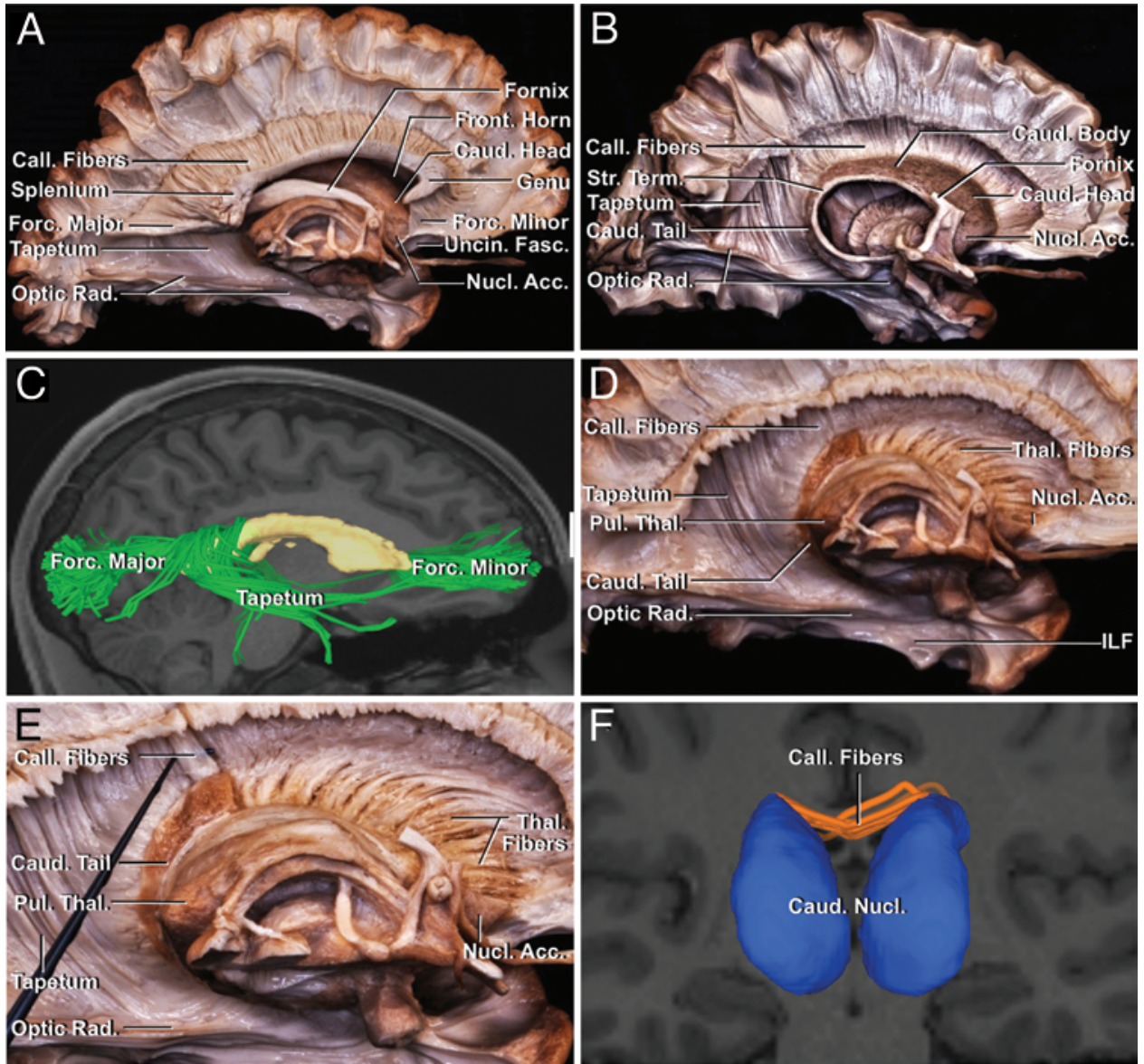

FIG. 14. A: Right hemisphere. Removing the cingulum and sledge runner fibers exposes the callosal fibers. The forceps minor forms the superomedial wall and roof of the frontal horn, which are also covered by the fibers of the body of the corpus callosum. The forceps major fibers cover the superior half of the medial wall of the atrium and continue to reach the occipital lobe. The tapetum covers the roof and lateral wall of the atrium and the temporal horn. B: Removing the dorsal part of the callosal fibers from the midline to the level of the centrum semiovale exposes the caudate nucleus and the ventral callosal fibers, which run inferior to the caudate nucleus and cover the entire lateral surface of the lateral ventricle. The tapetal fibers cover the lateral wall of the atrium and the temporal horn. C: MR tractography showing the forceps minor and major and tapetum (green) fibers in relationship to the lateral ventricle. D: The body and head of the caudate nucleus were removed to expose the anterior and superior frontal thalamic radiations. E: A small bundle of callosal fibers has been retracted to show the relationship between the ventral callosal fibers and thalamic radiations. F: MR tractography showing the ventral fibers of the corpus callosum (orange) connecting the bodies of the caudate nuclei bilaterally $($ blue $)$. Acc. = accumbens; Call. = callosal; Caud. = caudate; Fasc. $=$ fasciculus; Forc. = forceps; Front. = frontal; ILF = inferior longitudinal fasciculus; Nucl. = nucleus; Pul. = pulvinar; Rad. = radiations; Str. = stria; Term. = terminalis; Thal. $=$ thalami $=$ thalamic.

confusion, digital agnosia, agraphia, and acalculia), and visual memory loss and neglect in the nondominant hemisphere, due to damage of the SLF II and dorsal part of the AF (Tables 2 and 3).

Proximal Sylvian. Wieser and Yaşargil described the proximal transsylvian transamygdalar approach to the temporal horn, suggested for selective amygdalohippocampectomy in patients with mesial temporal sclerosis (Fig. 16; Table 3). ${ }^{114}$ This approach, which minimizes the risk to Meyer's loop, requires a cortical incision through the cortex overlying the amygdala. ${ }^{114,120}$ Based on our fiber dissections and MR tractography studies, the posterior part of the UF, temporal extension of the anterior commissure, Li-Am fasciculus, and cingulum fibers can be damaged in this approach. This approach may cross the anterior loop of the optic radiations, based on reports of postoperative visual field defects (Tables 2 and 3). ${ }^{120}$ Inconsistency of postoperative results regarding visual field defects may be caused by optic radiation variability and/ or indirect injury of the optic radiations. ${ }^{120}$ Transecting the UF, as is possibly needed for good results in epilepsy surgery, may result in the patient's inability to name wellknown objects. ${ }^{6,32,37,114,120}$ Although Yaşargil et al. reported no long-term memory deficits after selective amygdalohippocampectomy, some authors have reported long-term memory deficits possibly related to variation in the memory testing method and not the surgical procedure..$^{32,37,114,120}$

Distal Sylvian. This approach, directed through a small insular incision adjacent to the posterior insular point, can be used to remove small lesions in the atrium (Fig. 16). ${ }^{48,97}$ 

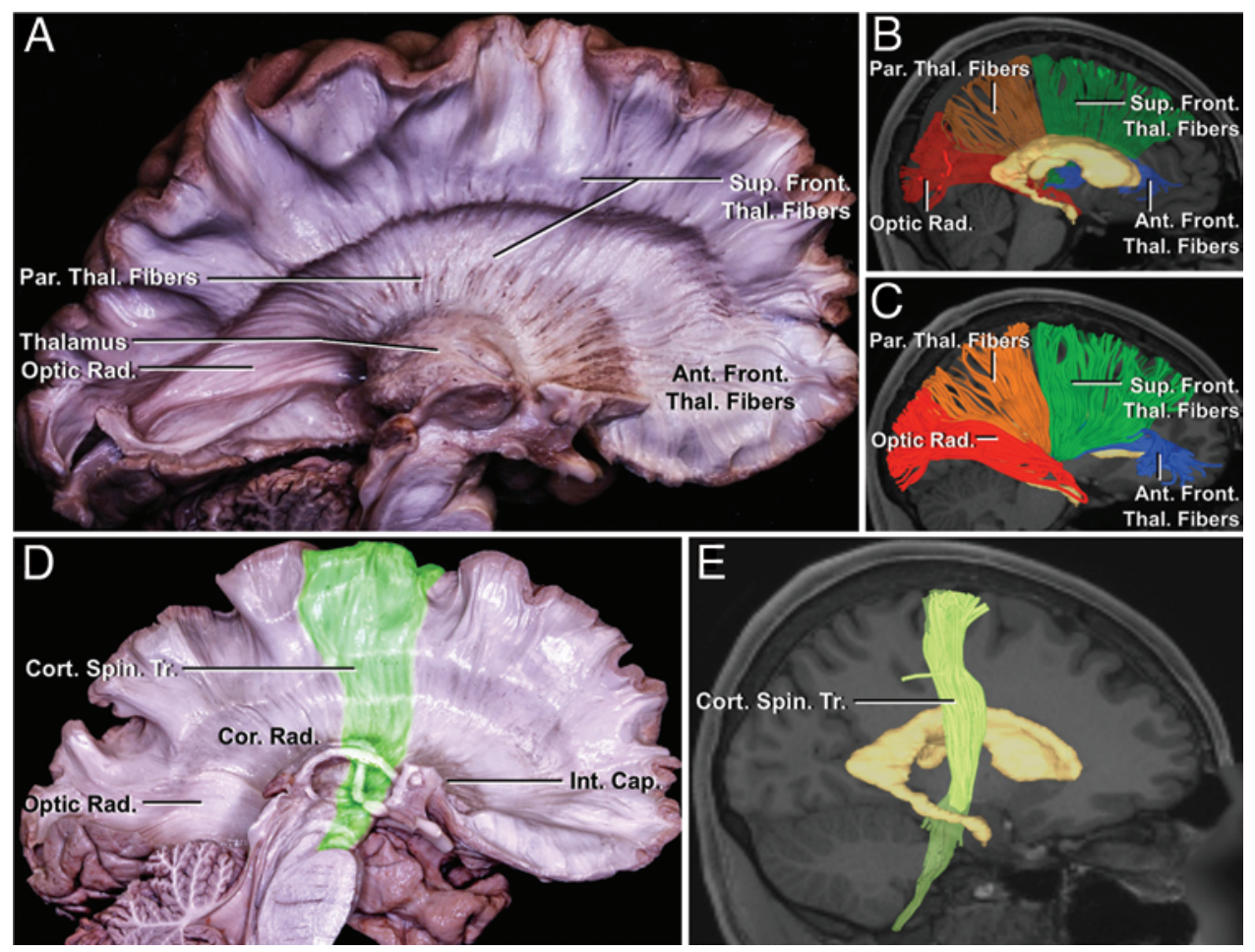

FIG. 15. A: Removing the callosal fibers exposes the thalamic radiations, which are divided into 5 thalamic radiations: anterior frontal, superior frontal, parietal, occipital, and inferior. The anterior frontal thalamic radiations are positioned lateral to the inferior two-thirds of the frontal horn. The superior frontal thalamic radiations are positioned lateral to the superior one-third of the frontal horn and anterior two-thirds of the body. The parietal thalamic radiations are positioned lateral to the posterior one-third of the body and superior one-third of the atrium. The occipital thalamic radiations (optic radiations) run lateral to the temporal horn and the inferior two-thirds of the atrium. B: MR tractography showing the thalamic radiations (parietal in orange, superior frontal in green, and anterior frontal in blue) and optic radiations (red) in relation to the lateral ventricle from medial. C: MR tractography from lateral showing the thalamic radiations (parietal in orange, superior frontal in green, and anterior frontal in blue) and optic radiations $(r e d)$ in relation to the lateral ventricle from lateral. D: The optic radiations are preserved. Removing the thalamic radiations exposes the internal capsule fibers and corona radiata. The corticospinal tract (light green) is positioned lateral to the body of the lateral ventricle. E: MR tractography showing the corticospinal tract (light green) in relation to the lateral ventricle. Ant. = anterior; Cap. = capsule; Cor. = corona; Cort. = cortico; Front. = frontal; Int. = internal; Par. = parietal; Rad. = radiata = radiations; Spin. = spinal; Sup. = superior; Thal. $=$ thalamic; $\operatorname{Tr}$. $=$ tract.

Opening the sylvian fissure allows a wide operating field, but it risks damaging the caudate tail, optic radiations, posterior part of the corona radiata, AF, and MdLF (Table 3).

Subtemporal. This approach, directed through the occipitotemporal gyrus or the collateral sulcus on the inferior surface of the temporal lobe, has been used to access the posterior part of the hippocampus and the inferior part of the atrium for amygdalohippocampectomy without any visual or memory deficits. ${ }^{39,48,84}$ Based on our dissections, the Li-Am fasciculus may be damaged in this approach (Fig. 16; Table 3).

\section{Periventricular Tracts in Hydrocephalus}

Normal pressure hydrocephalus (NPH), a treatable clinical syndrome developing in the elderly that causes cognitive disorder, gait abnormalities, and urinary incontinence, remains a major challenge because its clinical presentation overlaps with that of Alzheimer's disease (AD) and Parkinson's disease (PD) and makes the selection of patients for surgery difficult. MR tractography has been recommended as a means of differentiating among NPH, AD, and PD. ${ }^{36,38,40,47,50,52,65,66,76}$ Hydrocephalus studies have suggested that the compression indicated by high fractional anisotropy (FA) levels will eventually cause the neuronal degeneration, brain edema, or deterioration of the white matter indicated by low FA levels. ${ }^{40,58}$

\section{Corpus Callosum}

In our dissections and tractography studies, the most extensive tract related to all parts of the lateral ventricle is the corpus callosum with its most ventral fibers being the first and most affected by hydrocephalus. ${ }^{40,47,66,80} \mathrm{Re}-$ cent studies have reported lower FA in NPH than in AD or PD in the corpus callosum. ${ }^{65,66}$ Mataró et al. and Hoza et al. showed a negative correlation between the size of the frontal fibers of the corpus callosum and mild impairment of attention and executive function in idiopathic NPH. ${ }^{40,66}$ The study by Hoza et al. supports the hypothesis that in $\mathrm{NPH}$, gait disturbance, at least, might be explained by chronic damage to the corticospinal tract. ${ }^{40}$

\section{Corona Radiata}

These fibers pass lateral to the ventricles and should have a lower risk of being compressed than the corpus 


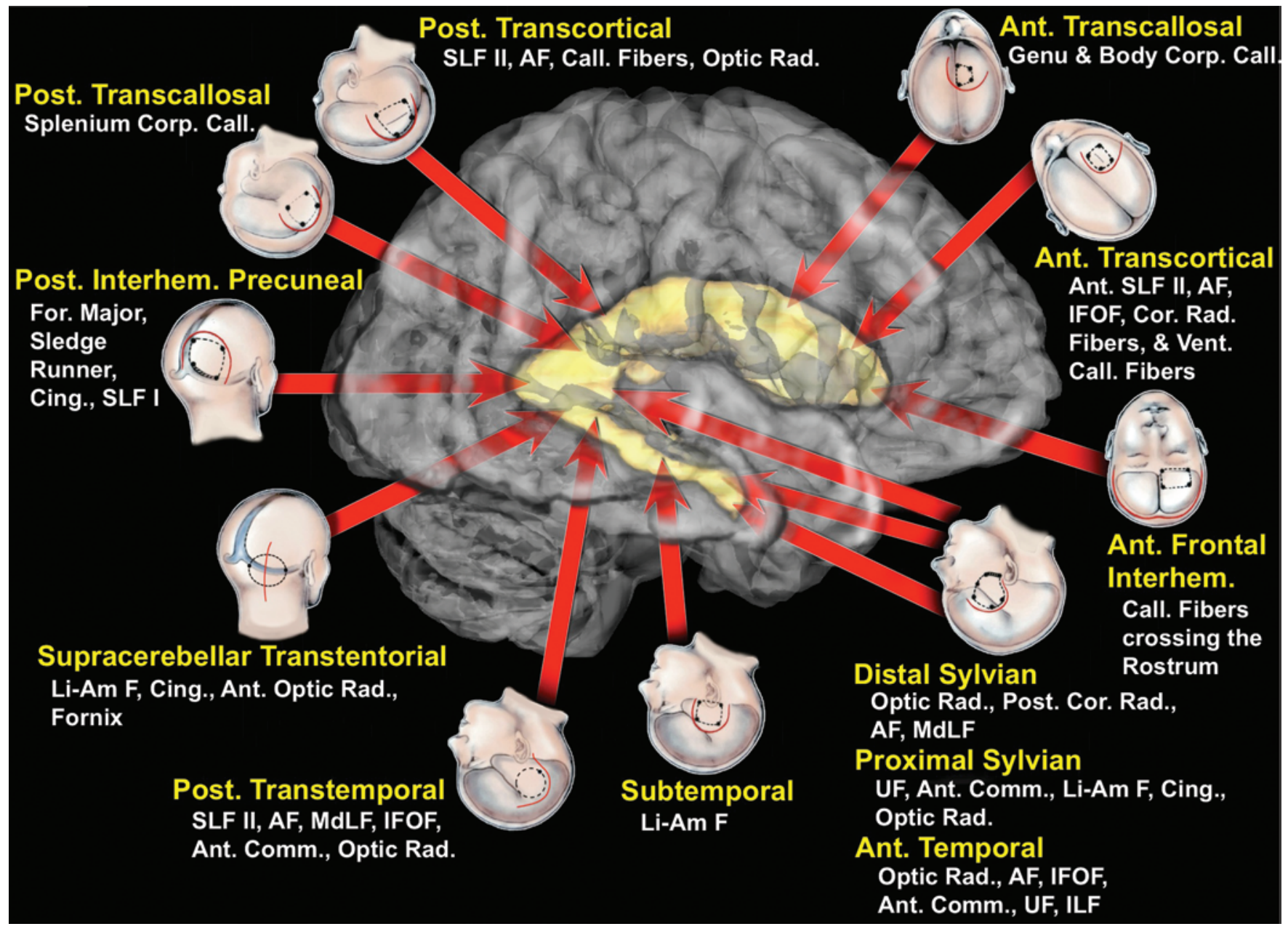

FIG. 16. Surgical approaches to the lateral ventricle. The skin incision (solid line) and craniotomy flap (broken line) and their routes to the ventricle (red arrows) are shown for each reviewed approach. Related tracks at risk are listed below the operative approaches. The supracerebellar transtentorial transcollateral and paramedian supracerebellar-transtentorial approaches from Table 3 have been combined for listing of the fiber tracts at risk. $\mathrm{AF}=$ arcuate fasciculus; Ant. = anterior; Call. = callosal = callosum; Cing . = cingulum; Comm. = commissure; Cor. = corona; Corp. = corpus; Forc. = forceps; IFOF = inferior frontooccipital fasciculus; ILF = inferior longitudinal fasciculus; Interhem. = interhemispheric; Li-Am F = lingular amygdaloidal fibers; MdLF = middle longitudinal fasciculus; Post. = posterior; Rad. $=$ radiata = radiations; SLF = superior longitudinal fasciculus; UF $=$ uncinate fasciculus; Vent. = ventral.

callosum because the ventral callosal fibers and caudate nucleus form a barrier between the corona radiata and ventricle wall. However, in NPH the posterior part of the corona radiata fibers may have increased FA (compressed but without secondary damage). ${ }^{76}$ The anterior part of the corona radiata, positioned around the frontal horns, will be affected first, followed by the posterior part, relatively far from the frontal horns. ${ }^{40,50}$ Increased FA in the posterior part of the corona radiata suggests a shunt-responsive NPH, as differentiated from other dementias. ${ }^{50}$ Decompression of the anterior part of the corona radiata, which contains fibers that connect to the supplementary motor, primary motor, and sensory areas, has been shown to improve gait disturbance. ${ }^{50,65}$ Cognitive decline and incontinence also fit with impairment of the anterior part of the corona radiata. ${ }^{40}$

\section{Hippocampus}

The hippocampus, a critical structure for learning and memory formation, is thought to be affected more in patients with hydrocephalus because of its position, bathed in cerebrospinal fluid in the temporal horn. Hong et al. reported that patients with AD had significantly lower FA values in the hippocampus than patients with NPH and healthy controls, without significant differences in hippocampal volume. ${ }^{38}$ They concluded that hippocampal FA may be a sensitive biomarker for differentiating AD from NPH; nevertheless, patients with NPH had lower FA levels than healthy controls. ${ }^{38}$

\section{Fornix}

The fornix has a close relationship with the lateral ventricle, suggesting that cognitive deficits, such as memory impairment, and executive and visuospatial dysfunction in NPH patients might be related to forniceal damage. ${ }^{36,124}$ Hattori et al. reported a significantly lower-volume, mean cross-sectional area (dividing the volume of the fornix by 
the length of the fornix) and FA, and greater fornix length in patients with NPH compared with patients with AD or control subjects. ${ }^{36}$

\section{Optic Radiations, AF, and SLF}

Lower FA values for the optic radiations and the SLF (in this case meaning the combined AF and SLF) were reported in patients with hydrocephalus than in the control groups, but the differences were slight and not statistically significant. ${ }^{4}$

\section{Caudate Nucleus}

This nucleus is at risk for damage in hydrocephalus because of its close relationship with the ventricle walls. Osuka et al. reported higher caudate nucleus FA values that increased rapidly after surgery in NPH patients compared with the atrophy group, and they suggested that evaluation of caudate nucleus FA values can be used to differentiate NPH from other diseases. ${ }^{76}$ Changes in the construction of the human caudate by hydrocephalus or dementia can result in a variety of neurological and psychiatric disorders. ${ }^{34,85}$

\section{Thalamus}

Although the thalamus is located in the center of the lateral ventricle, its FA values do not change in tractography studies related to NPH. This can be explained by its rigid composition. ${ }^{76}$ Additionally, Lundin et al. found a significant decrease in total $\mathrm{N}$-acetyl compounds and $\mathrm{N}$ acetyl aspartate in the thalamus of NPH patients compared with healthy groups in an MR spectroscopy study. Total $N$-acetyl and $N$-acetyl aspartate are related with neuronal density. Lundin et al. suggested that the distribution of cortico-basal ganglia-thalamocortical circuits, including the supplementary motor cortex, can cause impaired movement and gait disturbance in patients with $\mathrm{NPH} .{ }^{56}$

\section{Conclusions}

This is the first study combining fiber dissection techniques, MR tractography, and transillumination technique to describe the fiber tracts related to the ventricles and to further examine their relationships in each of multiple approaches to the ventricles. In addition, this study is the first to examine and discuss the anatomy of fiber pathways of the brain and syndromes related to ventricular enlargement by virtue of fiber dissection technique. Some of the first-time fiber dissection and tractography findings displayed in this study include the following: 1) the relationship between the parts of the lateral ventricle and the SLF II and III, VOF, anterior and posterior parts of the MdLF, sledge runner fasciculus, anterior crus of the anterior commissure and its temporal and occipital extensions, internal capsule, thalamic radiations, cingulum, and corticospinal tract; 2) new subdivision of the AF into superior, middle, and inferior parts and their relationship to parts of the lateral ventricles; 3) subdivisions of the IFOF into anterior and posterior parts in relation to the temporal and occipital horns; 4) new subdivisions of the UF into anterosuperior and posteroinferior parts in relation to the frontal and temporal horn; 5) the course of retro- and sublenticular parts of the internal capsule joining the sagittal stratum;
6) 3 distinct subcomponents of optic radiations, anterior, central, and posterior, based on their course and termination in relation to the parts of the lateral ventricle; 7) new subdivision of the callosal fibers into dorsal and ventral parts; 8) the relationship between the tapetum, connecting to the caudate nucleus, and the superior and lateral wall of the atrium and temporal horn; 9) delineation of the Li-Am fasciculus, in both MR tractography and fiber dissection, and definition of its course in relation to the cingulum, optic radiations, ILF, sledge runner, and other short association fibers, in addition to the atrium and temporal horn; 10) demonstration of the fibers interconnecting the paired caudate nuclei; and 11) the white matter tracts at risk in each of multiple operative approaches to the ventricles. These findings are summarized in Table 1 . Understanding the relationship of the white matter tracts to the parts of the lateral ventricle should aid in planning safe and accurate approaches within the cerebrum and lateral ventricles and yield a better understanding of pre- and postoperative symptoms. Tractography studies could play a role in selecting patients most likely to benefit from shunt surgery for NPH.

\section{Acknowledgments}

MR tractography data were provided in part by the Human Connectome Project, WU-Minn Consortium (principal investigators: David Van Essen and Kamil Ugurbil; 1U54MH091657), funded by the $16 \mathrm{NIH}$ Institutes and Centers that support the NIH Blueprint for Neuroscience Research; and by the McDonnell Center for Systems Neuroscience at Washington University.

Abuzer Güngör was funded by The Scientific and Technological Research Council of Turkey, International Postdoctoral Research Scholarship Programme (grant no. 1059B191401047).

This work was also supported by the University of Florida Foundation.

We deeply appreciate the continuous support provided by Robin Barry in preparation of the figures and by Jessica Striley with the manuscript.

\section{References}

1. Al-Otaibi F, Baeesa SS, Parrent AG, Girvin JP, Steven D: Surgical techniques for the treatment of temporal lobe epilepsy. Epilepsy Res Treat 2012:374848, 2012

2. Andersson JLR, Skare S, Ashburner J: How to correct susceptibility distortions in spin-echo echo-planar images: application to diffusion tensor imaging. Neuroimage 20:870-888, 2003

3. Andersson JLR, Xu J, Yacoub E, Auerbach E, Moeller S, Ugurbil K: A comprehensive Gaussian process framework for correcting distortions and movements in diffusion images. Proc Int Soc Mag Reson Med 20:2426, 2012 (Abstract)

4. Assaf Y, Ben-Sira L, Constantini S, Chang LC, Beni-Adani L: Diffusion tensor imaging in hydrocephalus: initial experience. AJNR Am J Neuroradiol 27:1717-1724, 2006

5. Barton JJ, Hefter R, Chang B, Schomer D, Drislane F: The field defects of anterior temporal lobectomy: a quantitative reassessment of Meyer's loop. Brain 128:2123-2133, 2005

6. Beis JM, Keller C, Morin N, Bartolomeo P, Bernati T, Chokron S, et al: Right spatial neglect after left hemisphere stroke: qualitative and quantitative study. Neurology 63:1600-1605, 2004

7. Benjamin CF, Singh JM, Prabhu SP, Warfield SK: Optimization of tractography of the optic radiations. Hum Brain Mapp 35:683-697, 2014 
8. Binder JR, Frost JA, Hammeke TA, Cox RW, Rao SM, Prieto T: Human brain language areas identified by functional magnetic resonance imaging. J Neurosci 17:353-362, 1997

9. Bohnstedt BN, Kulwin CG, Shah MV, Cohen-Gadol AA: Posterior interhemispheric transfalcine transprecuneus approach for microsurgical resection of periatrial lesions: indications, technique, and outcomes. J Neurosurg 123:1045-1054, 2015

10. Bookheimer S: Functional MRI of language: new approaches to understanding the cortical organization of semantic processing. Annu Rev Neurosci 25:151-188, 2002

11. Cauley KA, Cataltepe O: Axial diffusivity of the corona radiata correlated with ventricular size in adult hydrocephalus. AJR Am J Roentgenol 203:170-179, 2014

12. Cavanna AE, Trimble MR: The precuneus: a review of its functional anatomy and behavioural correlates. Brain 129:564-583, 2006

13. Chan-Seng E, Moritz-Gasser S, Duffau H: Awake mapping for low-grade gliomas involving the left sagittal stratum: anatomofunctional and surgical considerations. J Neurosurg 120:1069-1077, 2014

14. Chechlacz M, Rotshtein P, Hansen PC, Deb S, Riddoch MJ, Humphreys GW: The central role of the temporo-parietal junction and the superior longitudinal fasciculus in supporting multi-item competition: evidence from lesion-symptom mapping of extinction. Cortex 49:487-506, 2013

15. Cuomo J, Flaster M, Biller J: Right Brain: A reading specialist with alexia without agraphia: Teacher interrupted. Neurology 82:e5-e7, 2014

16. Davies J, Tawk RG, Lawton MT: The contralateral transcingulate approach: operative technique and results with vascular lesions. Neurosurgery 71 (1 Suppl Operative):4-14, 2012

17. De Benedictis A, Duffau H, Paradiso B, Grandi E, Balbi S, Granieri E, et al: Anatomo-functional study of the temporoparieto-occipital region: dissection, tractographic and brain mapping evidence from a neurosurgical perspective. J Anat 225:132-151, 2014

18. Ding X, Wu J, Zhou Z, Zheng J: Specific locations within the white matter and cortex are involved in the cognitive impairments associated with periventricular white matter lesions (PWMLs). Behav Brain Res 289:9-18, 2015

19. Duffau H: The "frontal syndrome" revisited: lessons from electrostimulation mapping studies. Cortex 48:120-131, 2012

20. Duffau H: Lessons from brain mapping in surgery for lowgrade glioma: insights into associations between tumour and brain plasticity. Lancet Neurol 4:476-486, 2005

21. Duffau H, Capelle L, Sichez N, Denvil D, Lopes M, Sichez JP, et al: Intraoperative mapping of the subcortical language pathways using direct stimulations. An anatomo-functional study. Brain 125: 199-214, 2002

22. Ellenbogen RG: Transcortical surgery for lateral ventricular tumors. Neurosurg Focus 10(6):E2, 2001

23. Feinberg DA, Moeller S, Smith SM, Auerbach E, Ramanna S, Gunther M, et al: Multiplexed echo planar imaging for sub-second whole brain FMRI and fast diffusion imaging. PLoS One 5:e15710, 2010 (Erratum in PLoS One 6:10.1371/annotation/d9496d01-8c5d-4d24-828794449ada5064, 2011)

24. Fernández -Miranda JC, Pathak S, Engh J, Jarbo K, Verstynen T, Yeh FC, et al: High-definition fiber tractography of the human brain: neuroanatomical validation and neurosurgical applications. Neurosurgery 71:430-453, 2012

25. Fernández-Miranda JC, Rhoton AL Jr, Alvarez-Linera J, Kakizawa Y, Choi C, de Oliveira EP: Three-dimensional microsurgical and tractographic anatomy of the white matter of the human brain. Neurosurgery 62 (6 Suppl 3): 989 1028,2008

26. Fernández-Miranda JC, Wang Y, Pathak S, Stefaneau L, Verstynen T, Yeh FC: Asymmetry, connectivity, and segmentation of the arcuate fascicle in the human brain. Brain Struct Funct 220: 1665-1680, 2015

27. Fischl B: FreeSurfer. Neuroimage 62:774-781, 2012

28. Gerstmann J: Zur symptomatologie der hirnläsionen im übergangsgebiet der unteren parietal und mittleren occipitalwindung. Nervenarzt 3:691-695, 1930

29. Ghosh GN, Wycoco V, Ghosh S: Transient visual hallucinations due to posterior callosal stroke. J Stroke Cerebrovasc Dis 24:e147-e148, 2015

30. Glasser MF, Rilling JK: DTI tractography of the human brain's language pathways. Cereb Cortex 18:2471-2482, 2008

31. Glasser MF, Sotiropoulos SN, Wilson JA, Coalson TS, Fischl B, Andersson JL, et al: The minimal preprocessing pipelines for the Human Connectome Project. Neuroimage 80:105-124, 2013

32. Gleissner U, Helmstaedter C, Schramm J, Elger CE: Memory outcome after selective amygdalohippocampectomy: a study in 140 patients with temporal lobe epilepsy. Epilepsia 43:87-95, 2002

33. Goga C, Türe U: The anatomy of Meyer's loop revisited: changing the anatomical paradigm of the temporal loop based on evidence from fiber microdissection. J Neurosurg 122: $1253-1262,2015$

34. Grahn JA, Parkinson JA, Owen AM: The cognitive functions of the caudate nucleus. Prog Neurobiol 86:141-155, 2008

35. Grossi D, Soricelli A, Ponari M, Salvatore E, Quarantelli M, Prinster A, et al: Structural connectivity in a single case of progressive prosopagnosia: the role of the right inferior longitudinal fasciculus. Cortex 56:111-120, 2014

36. Hattori T, Sato R, Aoki S, Yuasa T, Mizusawa H: Different patterns of fornix damage in idiopathic normal pressure hydrocephalus and Alzheimer disease. AJNR Am J Neuroradiol 33:274-279, 2012

37. Helmstaedter C, Elger CE, Hufnagel A, Zentner J, Schramm $\mathrm{J}$ : Different effects of left anterior temporal lobectomy, selective amygdalohippocampectomy, and temporal cortical lesionectomy on verbal learning, memory, and recognition. J Epilepsy 9:39-45, 1996

38. Hong YJ, Yoon B, Shim YS, Cho AH, Lim SC, Ahn KJ, et al: Differences in microstructural alterations of the hippocampus in Alzheimer disease and idiopathic normal pressure hydrocephalus: a diffusion tensor imaging study. AJNR Am J Neuroradiol 31:1867-1872, 2010

39. Hori T, Yamane F, Ochiai T, Kondo S, Shimizu S, Ishii K, et al: Selective subtemporal amygdalohippocampectomy for refractory temporal lobe epilepsy: operative and neuropsychological outcomes. J Neurosurg 106:134-141, 2007

40. Hoza D, Vlasák A, Hořínek D, Sameš M, Alfieri A: DTIMRI biomarkers in the search for normal pressure hydrocephalus aetiology: a review. Neurosurg Rev 38:239-244, 2015

41. Izci Y, Seçkin H, Ateş O, Başkaya MK: Supracerebellar transtentorial transcollateral sulcus approach to the atrium of the lateral ventricle: microsurgical anatomy and surgical technique in cadaveric dissections. Surg Neurol 72:509_ 514,2009

42. Jacobs HI, Gronenschild EH, Evers EA, Ramakers IH, Hofman PA, Backes WH, et al: Visuospatial processing in early Alzheimer's disease: a multimodal neuroimaging study. Cortex 64:394-406, 2015

43. Jenkinson M, Bannister P, Brady M, Smith S: Improved optimization for the robust and accurate linear registration and motion correction of brain images. Neuroimage 17:825-841, 2002 
44. Jenkinson M, Beckmann CF, Behrens TE, Woolrich MW, Smith SM: FSL. Neuroimage 62:782-790, 2012

45. Juretschke FR, Güresir E, Marquardt G, Berkefeld J, Rosahl $\mathrm{S}$, Klisch J, et al: Trigonal and peritrigonal lesions of the lateral ventricle-surgical considerations and outcome analysis of 20 patients. Neurosurg Rev 33:457-464, 2010

46. Kamali A, Flanders AE, Brody J, Hunter JV, Hasan KM: Tracing superior longitudinal fasciculus connectivity in the human brain using high resolution diffusion tensor tractography. Brain Struct Funct 219:269-281, 2014

47. Kanno S, Abe N, Saito M, Takagi M, Nishio Y, Hayashi A, et al: White matter involvement in idiopathic normal pressure hydrocephalus: a voxel-based diffusion tensor imaging study. J Neurol 258:1949-1957, 2011

48. Kawashima M, Li X, Rhoton AL Jr, Ulm AJ, Oka H, Fujii $\mathrm{K}$ : Surgical approaches to the atrium of the lateral ventricle: microsurgical anatomy. Surg Neurol 65:436-445, 2006

49. Keser Z, Ucisik-Keser FE, Hasan KM: Quantitative mapping of human brain vertical-occipital fasciculus. J Neuroimaging 26:188-193, 2016

50. Kim MJ, Seo SW, Lee KM, Kim ST, Lee JI, Nam DH, et al: Differential diagnosis of idiopathic normal pressure hydrocephalus from other dementias using diffusion tensor imaging. AJNR Am J Neuroradiol 32:1496-1503, 2011

51. Klingler J: Erleichterung der makroskopischen Praeparation des Gehirns durch den Gefrierprozess. Schweiz Arch Neurol Psychiatr 36:247-256, 1935

52. Koyama T, Marumoto K, Domen K, Miyake H: White matter characteristics of idiopathic normal pressure hydrocephalus: a diffusion tensor tract-based spatial statistic study. Neurol Med Chir (Tokyo) 53:601-608, 2013

53. Latini F: New insights in the limbic modulation of visual inputs: the role of the inferior longitudinal fasciculus and the Li-Am bundle. Neurosurg Rev 38:179-190, 2015

54. Latini F, Hjortberg M, Aldskogius H, Ryttlefors M: The classical pathways of occipital lobe epileptic propagation revised in the light of white matter dissection. Behav Neurol 2015:872645, 2015

55. Le Gars D, Lejeune JP, Peltier J: Surgical anatomy and surgical approaches to the lateral ventricles. Adv Tech Stand Neurosurg 34:147-187, 2009

56. Lundin F, Tisell A, Leijon G, Leinhard OD, Davidsson L, Grönqvist A, et al: Preoperative and postoperative 1H-MR spectroscopy changes in frontal deep white matter and the thalamus in idiopathic normal pressure hydrocephalus. $\mathbf{J}$ Neurol Neurosurg Psychiatry 84:188-193, 2013

57. Ma J, Cheng L, Wang G, Lin S: Surgical management of meningioma of the trigone area of the lateral ventricle. World Neurosurg 82:757-769, 2014

58. Madhavan S, Campbell SK, Campise-Luther R, GaeblerSpira D, Zawacki L, Clark A, et al: Correlation between fractional anisotropy and motor outcomes in one-year-old infants with periventricular brain injury. J Magn Reson Imaging 39:949-957, 2014

59. Mahaney KB, Abdulrauf SI: Anatomic relationship of the optic radiations to the atrium of the lateral ventricle: description of a novel entry point to the trigone. Neurosurgery 63 (4 Suppl 2): 195-203, 2008

60. Mahayana IT, Tcheang L, Chen CY, Juan CH, Muggleton NG: The precuneus and visuospatial attention in near and far space: a transcranial magnetic stimulation study. Brain Stimulat 7:673-679, 2014

61. Makris N, Papadimitriou GM, Kaiser JR, Sorg S, Kennedy DN, Pandya DN: Delineation of the middle longitudinal fascicle in humans: a quantitative, in vivo, DT-MRI study. Cereb Cortex 19:777-785, 2009

62. Maldonado IL, Moritz-Gasser S, de Champfleur NM, Bertram L, Moulinié G, Duffau H: Surgery for gliomas involving the left inferior parietal lobule: new insights into the functional anatomy provided by stimulation mapping in awake patients. J Neurosurg 115:770-779, 2011

63. Marcus HJ, Sarkar H, Mindermann T, Reisch R: Keyhole supracerebellar transtentorial transcollateral sulcus approach to the lateral ventricle. Neurosurgery 73 (2 Suppl Operative):onsE295-onsE301, 2013

64. Martino J, De Lucas EM: Subcortical anatomy of the lateral association fascicles of the brain: A review. Clin Anat 27:563-569, 2014

65. Marumoto K, Koyama T, Hosomi M, Kodama N, Miyake H, Domen K: Diffusion tensor imaging in elderly patients with idiopathic normal pressure hydrocephalus or Parkinson's disease: diagnosis of gait abnormalities. Fluids Barriers CNS 9:20, 2012

66. Mataró M, Matarín M, Poca MA, Pueyo R, Sahuquillo J, Barrios M, et al: Functional and magnetic resonance imaging correlates of corpus callosum in normal pressure hydrocephalus before and after shunting. J Neurol Neurosurg Psychiatry 78:395-398, 2007

67. Menjot de Champfleur N, Lima Maldonado I, MoritzGasser S, Machi P, Le Bars E, Bonafé A, et al: Middle longitudinal fasciculus delineation within language pathways: a diffusion tensor imaging study in human. Eur J Radiol 82:151-157, 2013

68. Mesulam MM: A cortical network for directed attention and unilateral neglect. Ann Neurol 10:309-325, 1981

69. Milardi D, Bramanti P, Milazzo C, Finocchio G, Arrigo A, Santoro G, et al: Cortical and subcortical connections of the human claustrum revealed in vivo by constrained spherical deconvolution tractography. Cereb Cortex 25:406-414, 2015

70. Milligan BD, Meyer FB: Morbidity of transcallosal and transcortical approaches to lesions in and around the lateral and third ventricles: a single-institution experience. Neurosurgery 67:1483-1496, 2010

71. Moeller S, Yacoub E, Olman CA, Auerbach E, Strupp J, Harel N, et al: Multiband multislice GE-EPI at 7 tesla, with 16-fold acceleration using partial parallel imaging with application to high spatial and temporal whole-brain fMRI. Magn Reson Med 63:1144-1153, 2010

72. Nieuwenhuys R, Voogd J, van Huijzen C: The Human Central Nervous System. New York: Springer, 2008, p 247

73. Nilsson D, Malmgren K, Rydenhag B, Frisén L: Visual field defects after temporal lobectomy - comparing methods and analysing resection size. Acta Neurol Scand 110:301-307, 2004

74. Nishizaki T: Surgical approaches for lateral ventricular trigone meningioma, in Monleon D (ed): MeningiomasManagement and Surgery. Rijeka, Croatia: InTech, 2012

75. Nishizaki T, Ikeda N, Nakano S, Okamura T, Abiko S: Occipital inter-hemispheric approach for lateral ventricular trigone meningioma. Acta Neurochir (Wien) 151:17171721,2009

76. Osuka S, Matsushita A, Yamamoto T, Saotome K, Isobe T, Nagatomo Y, et al: Evaluation of ventriculomegaly using diffusion tensor imaging: correlations with chronic hydrocephalus and atrophy. J Neurosurg 112:832-839, 2010

77. Park ES, Cho YH, Kim JH, Kim SJ, Khang SK, Kim CJ: Frontal transcortical approach in 12 central neurocytomas. Acta Neurochir (Wien) 154:1961-1972, 2012

78. Parker GJ, Luzzi S, Alexander DC, Wheeler-Kingshott CA, Ciccarelli O, Lambon Ralph MA: Lateralization of ventral and dorsal auditory-language pathways in the human brain. Neuroimage 24:656-666, 2005

79. Párraga RG, Ribas GC, Welling LC, Alves RV, de Oliveira E: Microsurgical anatomy of the optic radiation and related fibers in 3-dimensional images. Neurosurgery 71 (1 Suppl Operative): $160-172,2012$ 
80. Pavlova MA, Krägeloh-Mann I: Limitations on the developing preterm brain: impact of periventricular white matter lesions on brain connectivity and cognition. Brain 136:9981011,2013

81. Peltier J, Roussel M, Gerard Y, Lassonde M, Deramond H, Le Gars D, et al: Functional consequences of a section of the anterior part of the body of the corpus callosum: evidence from an interhemispheric transcallosal approach. J Neurol 259:1860-1867, 2012 (Erratum in J Neurol 260:1199, 2013)

82. Piepmeier JM, Spencer DD, Sass KJ, George TM: Lateral ventricular masses, in Apuzzo MLJ (ed): Brain Surgery: Complication Avoidance and Management. New York: Churchill Livingstone, 1993, pp 581-599

83. Raybaud C: The corpus callosum, the other great forebrain commissures, and the septum pellucidum: anatomy, development, and malformation. Neuroradiology 52:447-477, 2010

84. Rhoton AL Jr: The lateral and third ventricles. Neurosurgery 51 (4 Suppl):S207-S271, 2002

85. Robinson JL, Laird AR, Glahn DC, Blangero J, Sanghera MK, Pessoa L, et al: The functional connectivity of the human caudate: an application of meta-analytic connectivity modeling with behavioral filtering. Neuroimage 60:117129,2012

86. Sarubbo S, De Benedictis A, Maldonado IL, Basso G, Duffau H: Frontal terminations for the inferior fronto-occipital fascicle: anatomical dissection, DTI study and functional considerations on a multi-component bundle. Brain Struct Funct 218:21-37, 2013

87. Sarubbo S, De Benedictis A, Milani P, Paradiso B, Barbareschi M, Rozzanigo U, et al: The course and the anatomo-functional relationships of the optic radiation: a combined study with 'post mortem' dissections and 'in vivo' direct electrical mapping. J Anat 226:47-59, 2015

88. Schmahmann JD, Pandya DN: Fiber Pathways of the Brain. Oxford, UK: Oxford University Press, 2006, pp 393-409, 501-530

89. Schramm J: Meningiomas of the trigone. World Neurosurg 83:486-487, 2015

90. Seger CA, Cincotta CM: The roles of the caudate nucleus in human classification learning. J Neurosci 25:2941-2951, 2005

91. Setsompop K, Gagoski BA, Polimeni JR, Witzel T, Wedeen VJ, Wald LL: Blipped-controlled aliasing in parallel imaging for simultaneous multislice echo planar imaging with reduced g-factor penalty. Magn Reson Med 67:1210-1224, 2012

92. Sincoff EH, Tan Y, Abdulrauf SI: White matter fiber dissection of the optic radiations of the temporal lobe and implications for surgical approaches to the temporal horn. J Neurosurg 101:739-746, 2004

93. Smith CD, Lori NF, Akbudak E, Sorar E, Gultepe E, Shimony JS, et al: MRI diffusion tensor tracking of a new amygdalo-fusiform and hippocampo-fusiform pathway system in humans. J Magn Reson Imaging 29:1248-1261, 2009

94. Sun C, Xie T, Zhang X, Zhu W, Gu Y, Wang H: To repeat or to recreate: a contralateral posterior interhemispheric transfalcine transprecuneus approach for recurrent meningiomas at the trigone of the lateral ventricle. J Clin Neurosci 21:1968-1972, 2014

95. Szmuda T, Słoniewski P, Szmuda M, Waszak PM, Starzyńska A: Quantification of white matter fibre pathways disruption in frontal transcortical approach to the lateral ventricle or the interventricular foramen in diffusion tensor tractography. Folia Morphol (Warsz) 73:129-138, 2014

96. Takemura H, Rokem A, Winawer J, Yeatman JD, Wandell BA, Pestilli F: A major human white matter pathway between dorsal and ventral visual cortex. Cereb Cortex 26:2205-2214, 2016

97. Tanriöver N, Küçükyürük B, Aydin S: [Surgical approaches to the lateral and third ventricular lesions.] Turk Norosiruji Derg 24:26-41, 2014 (Turkish)

98. Tanriover N, Rhoton AL Jr, Kawashima M, Ulm AJ, Yasuda A: Microsurgical anatomy of the insula and the sylvian fissure. J Neurosurg 100:891-922, 2004

99. Thiebaut de Schotten M, Dell'Acqua F, Forkel SJ, Simmons A, Vergani F, Murphy DG, et al: A lateralized brain network for visuospatial attention. Nat Neurosci 14:12451246, 2011

100. Thiebaut de Schotten M, Dell'Acqua F, Valabregue R, Catani M: Monkey to human comparative anatomy of the frontal lobe association tracts. Cortex 48:82-96, 2012

101. Thomas B, Eyssen M, Peeters R, Molenaers G, Van Hecke P, De Cock P, et al: Quantitative diffusion tensor imaging in cerebral palsy due to periventricular white matter injury. Brain 128:2562-2577, 2005

102. Thomas C, Avram A, Pierpaoli C, Baker C: Diffusion MRI properties of the human uncinate fasciculus correlate with the ability to learn visual associations. Cortex 72:65-78, 2015

103. Tokunaga K, Tamiya T, Date I: Transient memory disturbance after removal of an intraventricular trigonal meningioma by a parieto-occipital interhemispheric precuneus approach: Case report. Surg Neurol 65:167-169, 2006

104. Türe U, Harput MV, Kaya AH, Baimedi P, Firat Z, Türe $\mathrm{H}$, et al: The paramedian supracerebellar-transtentorial approach to the entire length of the mediobasal temporal region: an anatomical and clinical study. Laboratory investigation. J Neurosurg 116:773-791, 2012

105. Vassal F, Schneider F, Sontheimer A, Lemaire JJ, Nuti C: Intraoperative visualisation of language fascicles by diffusion tensor imaging-based tractography in glioma surgery. Acta Neurochir (Wien) 155:437-448, 2013

106. Vergani F, Mahmood S, Morris CM, Mitchell P, Forkel SJ: Intralobar fibres of the occipital lobe: a post mortem dissection study. Cortex 56:145-156, 2014

107. Voigt K, Yaşargil MG: Cerebral cavernous haemangiomas or cavernomas. Incidence, pathology, localization, diagnosis, clinical features and treatment. Review of the literature and report of an unusual case. Neurochirurgia (Stuttg) 19:59-68, 1976

108. Von Der Heide RJ, Skipper LM, Klobusicky E, Olson IR: Dissecting the uncinate fasciculus: disorders, controversies and a hypothesis. Brain 136:1692-1707, 2013

109. Wang X, Pathak S, Stefaneanu L, Yeh FC, Li S, FernandezMiranda JC: Subcomponents and connectivity of the superior longitudinal fasciculus in the human brain. Brain Struct Funct [epub ahead of print], 2015

110. Wang Y, Fernández-Miranda JC, Verstynen T, Pathak S, Schneider W, Yeh FC: Rethinking the role of the middle longitudinal fascicle in language and auditory pathways. Cereb Cortex 23:2347-2356, 2013

111. Wassermann D, Makris N, Rathi Y, Shenton M, Kikinis R, Kubicki M, et al: On describing human white matter anatomy: the white matter query language. Med Image Comput Comput Assist Interv 16:647-654, 2013

112. Wendling AS, Hirsch E, Wisniewski I, Davanture C, Ofer I, Zentner J, et al: Selective amygdalohippocampectomy versus standard temporal lobectomy in patients with mesial temporal lobe epilepsy and unilateral hippocampal sclerosis. Epilepsy Res 104:94-104, 2013

113. Whittingstall K, Bernier M, Houde JC, Fortin D, Descoteaux M: Structural network underlying visuospatial imagery in humans. Cortex 56:85-98, 2014

114. Wieser HG, Yaşargil MG: Selective amygdalohippocampec- 
tomy as a surgical treatment of mesiobasal limbic epilepsy. Surg Neurol 17:445-457, 1982

115. Xu J, Moeller S, Strupp J, Auerbach EJ, Chen L, Feinberg DA, et al: Highly accelerated whole brain imaging using aligned-blipped-controlled-aliasing multiband EPI. Proc Int Soc Mag Reson Med 20:2306, 2012

116. Yagmurlu K, Middlebrooks EH, Tanriover N, Rhoton AL Jr. Fiber tracts of the dorsal language stream in the human brain. J Neurosurg [epub ahead of print November 20, 2015. DOI: $10.3171 / 2015.5$.JNS15455]

117. Yagmurlu K, Vlasak AL, Rhoton AL Jr: Three-dimensional topographic fiber tract anatomy of the cerebrum. Neurosurgery 11 (Suppl 2):274-305, 2015

118. Yaşargil MG: Microneurosurgery: Microneurosurgery of CNS Tumors. Stuttgart: Thieme, 1996, Vol IVB, pp 38-42, 56-57, 63-65, 313-318, 320-323

119. Yaşargil MG, Abdulrauf SI: Surgery of intraventricular tumors. Neurosurgery 62 (6 Suppl 3): 1029-1041, 2008

120. Yaşargil MG, Krayenbühl N, Roth P, Hsu SP, Yaşargil DC: The selective amygdalohippocampectomy for intractable temporal limbic seizures. J Neurosurg 112:168-185, 2010

121. Yeatman JD, Rauschecker AM, Wandell BA: Anatomy of the visual word form area: adjacent cortical circuits and long-range white matter connections. Brain Lang 125:146155,2013

122. Yeatman JD, Weiner KS, Pestilli F, Rokem A, Mezer A, Wandell BA: The vertical occipital fasciculus: a century of controversy resolved by in vivo measurements. Proc Natl Acad Sci U S A 111:E5214-E5223, 2014

123. Yeh FC, Wedeen VJ, Tseng WY: Generalized q-sampling imaging. IEEE Trans Med Imaging 29:1626-1635, 2010
124. Winn RH (ed): Youmans Neurological Surgery, ed 6. Philadelphia: Saunders, 2011

125. Zhu W, Xie T, Zhang X, Ma B, Wang X, Gu Y, et al: A solution to meningiomas at the trigone of the lateral ventricle using a contralateral transfalcine approach. World Neurosurg 80:167-172, 2013

\section{Disclosures}

The authors report no conflict of interest concerning the materials or methods used in this study or the findings specified in this paper.

\section{Author Contributions}

Conception and design: Rhoton, Güngör, Baydin, Middlebrooks, Tanriover. Acquisition of data: Rhoton, Güngör, Baydin, Middlebrooks. Analysis and interpretation of data: Rhoton, Güngör, Baydin, Middlebrooks. Drafting the article: all authors. Critically revising the article: Rhoton, Güngör, Tanriover, Isler. Reviewed submitted version of manuscript: Rhoton, Güngör, Tanriover, Isler. Approved the final version of the manuscript on behalf of all authors: Rhoton. Administrative/technical/material support: Rhoton. Study supervision: Rhoton.

\section{Correspondence}

Abuzer Güngör, Department of Neurosurgery, University of Florida, P.O. Box 100265, Gainesville, FL 32610. email: abuzergungor@gmail.com. 